\title{
Property Optimization in As-Quenched Martensitic Steel by Molybdenum and Niobium Alloying
}

\author{
Hardy Mohrbacher ${ }^{1,2}$ \\ 1 Department of Materials Engineering (MTM), KU Leuven, 3001 Leuven, Belgium; hm@niobelcon.net; \\ Tel.: +32-3-484-5260 \\ 2 NiobelCon bvba, 2970 Schilde, Belgium
}

Received: 8 February 2018; Accepted: 28 March 2018; Published: 3 April 2018

\begin{abstract}
Niobium microalloying is the backbone of modern low-carbon high strength low alloy (HSLA) steel metallurgy, providing a favorable combination of strength and toughness by pronounced microstructural refinement. Molybdenum alloying is established in medium-carbon quenching and tempering of steel by delivering high hardenability and good tempering resistance. Recent developments of ultra-high strength steel grades, such as fully martensitic steel, can be optimized by using beneficial metallurgical effects of niobium and molybdenum. The paper details the metallurgical principles of both elements in such steel and the achievable improvement of properties. Particularly, the underlying mechanisms of improving toughness and reducing the sensitivity towards hydrogen embrittlement by a suitable combination of molybdenum and niobium alloying will be discussed.
\end{abstract}

Keywords: martensitic steel; direct quenching; microalloying; hardenability; toughness; grain refinement; Hall-Petch coefficient; microalloy precipitates; hydrogen embrittlement

\section{Introduction}

As-quenched martensite is the hardest and strongest microstructure of low-carbon steel, yet is often considered to have a tendency for brittleness. Tempering treatment mitigates the properties of martensite by reducing the strength and simultaneously increasing toughness and ductility [1,2]. Quenched and tempered steels find many applications for components subjected to demanding operating conditions.

As-quenched martensite is being used particularly for applications with extreme strength or hardness demands. Such applications traditionally appear in the mining industry where hardness and strength are fundamental assets providing good functionality and sufficiently long life of components subjected to wear conditions. More recently, as-quenched martensite has gained sizeable market potential in the automotive industry for making crash-resistant car body components [3,4]. State-of-the-art car bodies use these steels typically with a tensile strength of around $1500 \mathrm{MPa}$. They can represent up to 40 percent of the car body weight. Furthermore, hot-rolled martensitic steel has potential in structural applications where ultra-high strength is required for weight reduction, for instance in mobile hoisting equipment [5]. Since in all these applications impact loading must be expected, sufficient upper shelf toughness over the temperature range of operation is required, demanding a correspondingly matching ductile-to-brittle transition temperature. Another significant problem perceived in all ultra-high strength steels is the sensitivity to hydrogen embrittlement [6]. The presence of diffusible interstitial hydrogen in such steel can cause unexpected brittle fracture or leads to so-called "delayed cracking" [7]. In that respect, optimization of as-quenched martensitic steel is necessary.

Principally, two different processing routes are practiced for producing flat rolled steel with martensitic microstructure. Re-austenitizing \& quenching is the traditional process by which the 
as-rolled steel, typically having ferritic-pearlitic microstructure, is austenitized at temperatures of 900 to $950{ }^{\circ} \mathrm{C}$ and subsequently quenched, generally using water as a cooling medium. This process is particularly used for plate products. Cold-rolled strip can be treated in this way using a continuous annealing line equipped with a water quenching section. In the so-called press hardening process, nowadays widely used by the automotive industry, quenching is achieved by solid-to-solid heat conduction between the hot sheet and the cold forming die. In the production of hot-rolled strip and plate, direct quenching from the rolling heat is increasingly often being practiced. This procedure makes the re-austenitizing process obsolete and thus allows for considerable energy savings and simpler logistics in the steel works. However, direct quenching from austenite, depending on rolling conditions and alloy concept, can lead to an anisotropic microstructure $[8,9]$.

This paper focuses on property improvement of as-quenched martensite utilizing the metallurgical functionality of niobium and molybdenum as alloying elements. In this approach, established knowledge on the most significant relationships between microstructure and properties are briefly reviewed. Subsequently, successful examples for dedicated application of niobium and molybdenum alloying for property optimization in re-austenitized quenched as well as direct quenched flat rolled martensitic steels will be demonstrated.

\section{Review of Microstructure-Property Relationships in Martensite}

The crystal structure of low-carbon lath martensite site is bcc, but at carbon contents in excess of $0.20 \%$ the structure becomes slightly tetragonal [10]. Quenched steel containing carbon higher than $0.5 \%$ forms more complicated microstructures, as lath martensite is gradually replaced by plate martensite and the fraction of retained austenite increases. In the basic microstructure of lath martensitic steel [11-15] each prior austenite grain is subdivided into packets (Figure 1) separated by high-angle grain boundaries. Packets are sub-divided into blocks, which can be separated by either low-angle or high-angle grain boundaries [13-16]. Given the need to minimize elastic energy, the same microstructural pattern is favored for all prior austenite grains of reasonable size. Accordingly, the block and packet sizes tend to scale linearly with the parent austenite grain size until the grain size becomes so small that surface effects become dominant. Maki et al. [14] analyzed correlations of substructure size and parent austenite size in detail. The packet size can never be larger than the prior austenite grain size and, hence, decreases with the latter. Larger austenite grains transform into a substructure consisting of several packets. For a prior austenite grain size finer than $10 \mu \mathrm{m}$ it is possible that some prior austenite grains consist of a single packet or even a single block. Yet, the effect of prior austenite grain size on the lath width appears to be small.

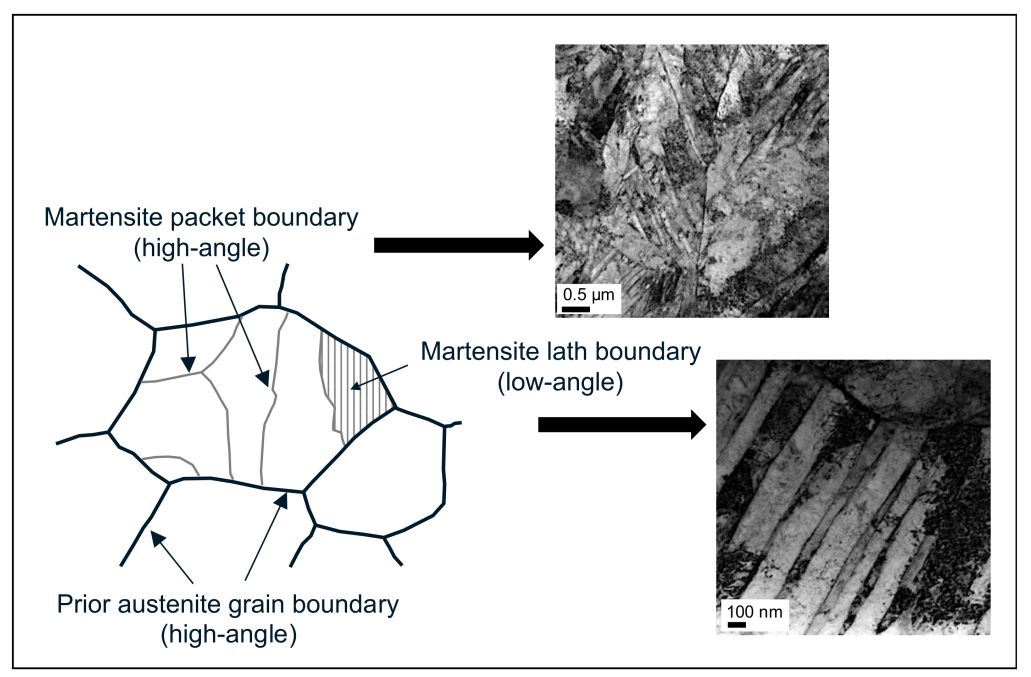

Figure 1. Microstructural features of low-carbon martensitic steel. 
It is well established that many important properties of polycrystalline materials are related to the grain size. Smaller grain size in ferritic steels increases strength and toughness while it lowers the ductile-to-brittle transition temperature according to Hall-Petch type relationships. In polygonal ferritic steels the grain size can easily be determined by light optical microscopy. In martensite, however, determination of the grain size is not trivial and often requires sophisticated microstructural analysis tools. Yet, the parent austenite grain size can be determined quite easily and, hence, is of great practical interest. With respect to properties, the fundamental question that needs to be answered is "which is the relevant definition for grain size in martensitic steel?". Morris and co-workers [17] have approached this question by defining an "effective" grain size $\left(d_{e f f}\right)$ in martensite and pointed out that it may be different with respect to the various properties.

\subsection{Effective Grain Size for Strength}

Early work by Cohen $[18,19]$ suggested the yield strength of carbon-free martensite to be inversely proportional to the square root of the parent austenite grain size as defined by

$$
\sigma_{y}=\sigma_{0}+K_{y} d_{e f f}^{-1 / 2}
$$

where $K_{y}$ is the Hall-Petch coefficient for strength. Later studies by Tomita and Okabayashi on Fe-0.20C-Ni-Cr-Mo steel, considered the packet size as the effective grain size in lath martensite [20]. This correlation could be well repeated by Wang et al. [21] on a similar steel although correlation with the parent austenite grain size was similarly good. Work by Morito and Obha [22] showed that the replacement of packet size by block size in the Hall-Petch relation of $\mathrm{Fe}-0.2 \mathrm{C}$ and $\mathrm{Fe}-0.2 \mathrm{C}-2 \mathrm{Mn}$ steels produced a more consistent value of the Hall-Petch coefficient. Also Morris [23] argued that the block size could be the effective grain size for strength. However, Bain variants share common slip planes and, hence, such block boundaries may not effectively inhibit slip [24]. Data by Ohmura and Tsuzaki [25] suggest that strengthening by block or packet boundaries is largely due to boundary decoration by carbon or carbide films. A detailed analysis of the effective grain size on strengthening in direct quenched steel was performed by Hannula et al. [26]. In these steels, austenite has a pronounced pancake morphology prior to quenching. Reduced thickness of the austenite pancake leads to smaller effective grain size. The effective grain size was determined by high-angle boundary misorientations $\left(>15^{\circ}\right)$ via an electron backscatter diffraction (EBSD) based technique, and its square root correlates well with the measured yield strength.

\subsection{Effective Grain Size for Toughness}

Two fracture modes, quasi-cleavage and ductile fracture, were observed by Irani [27] in an early study on the fracture behavior of martensitic steel. Under impact loading, the former absorbs less energy than the latter. The absorbed impact energy increases with the amount of ductile fractures. Quasi-cleavage proceeds by the nucleation and growth of submerged cracks ahead of the advancing fracture front. The crack front advances in a stepwise manner as the cracks in front of the fracture tip grow until coalescence takes place. The advance of a quasi-cleavage fracture crack through a martensitic structure is transgranular with respect to parent austenite grains or packets. The quasi-cleavage fracture surface shows characteristics of both true cleavage and plastic rupture.

Nailor et al. $[28,29]$ pointed out that micro-cracks formed within laths are too small to start cleavage due to the limited lath width. Micro-cracks in adjacent laths must join together to create a crack of critical length to propagate as cleavage. This crack experiences small deflections when crossing lath or sub-block boundaries and larger deflections or even crack arrest when passing block boundaries. The blocks are thought to coincide with the facets seen in fractography.

The cleavage fracture stress follows a relationship of the form:

$$
\sigma_{f}=K_{f} d_{e f f}^{-1 / 2}
$$


where $K_{f}$ is the Hall-Petch coefficient for cleavage. The microstructural mechanism of cleavage in bcc steels is well known; bcc steels cleave along $\{100\}$ planes. Consequently, in the case of lath martensitic steels the effective grain size $d_{\text {eff }}$ is the coherence length on $\{100\}$ planes, which determines the cleavage crack length. The $\{100\}$ coherence length is fixed by the "block" size, which is the basic crystallographic unit. Refining the block size in martensitic steel is hence an effective means of increasing its resistance to transgranular cleavage fracture, since Bain variant boundaries are crystallographic discontinuities in the $\{100\}$ cleavage planes [30].

The dimpled topography of ductile fracture is due to the concave depressions formed by the growth and coalescence of spherical micro-voids with the advancing crack front. These micro-voids may be nucleated at any heterogeneity; hence, the size and distribution of heterogeneities has an important influence on the formation, growth, and coalescence of voids. The size to which a micro-void can grow depends partly on the work-hardened state of the matrix. Thus, the number of voids required for the propagation of a fracture front will increase with an increase in the work hardened condition of the matrix. Improving the cleanness of steel is an important means of increasing energy absorption in ductile fracture mode. In very clean steels voids can be generated at grain corners defining the limit to this improvement effort.

\subsection{Effective Grain Size for Ductile-to-Brittle Transition Temperature}

Reducing the carbon content and refining the grain size can efficiently lower the ductile-to-brittle transition temperature in bcc steel. Grain refinement compensates the loss of strength originating from the carbon reduction. This principle has found its culmination in modern thermo-mechanical processed HSLA steels. The ductile-brittle transition temperature (DBTT) $T_{B}$ often obeys a constitutive equation of the form:

$$
T_{B}=T_{0}-K_{B} d_{e f f}^{-1 / 2}
$$

In martensitic steel the transition temperature from a ductile dimple-type fracture to brittle cleavage-type fracture depends on the block size and the strength. Reducing carbon is not always an option as carbon is needed for strength and the trade-off with Hall-Petch strengthening from grain refinement may be insufficient. The linear correlation between inverse square root of the packet size, thus, inherently block size and $T_{B}$ according to Equation (3) was demonstrated for different alloys $[29,30]$. The Hall-Petch coefficient $K_{B}$ was found to be larger in magnitude when the steel has higher carbon content [31].

The connection between DBTT and the cleavage fracture stress can be understood on the basis of a model that was originally suggested by the Russian physicist, Yoffee, in the early 20th century [32]. The ductile-brittle transition occurs at a temperature close to the crossover point. Accordingly, two generic ways of suppressing the ductile-brittle transition are feasible: raising the brittle fracture stress or lowering the yield strength. Since high yield strength is a prerequisite in many structural steels, most of the efforts have concentrated on raising the brittle fracture stress. Hanamura et al. [33] analyzed the impact of effective grain size on the cleavage fracture stress for various steel microstructures. The as-quenched martensitic microstructure according to their results has the largest Hall-Petch coefficient $K_{f}$ in Equation (2). For as-quenched martensite, $K_{f}$ was estimated to be around $160 \mathrm{~N} \cdot \mathrm{mm}^{-3 / 2}$ and is 4 times larger than that of ferritic-pearlitic steel.

\subsection{Effective Grain Size for Intergranular Embrittlement}

Under specific circumstances intergranular brittle fracture is observed. Parent austenite grains usually constitute the facets of that fracture type. Intergranular fracture occurs when the grain boundary cohesion is weaker than either yield strength and cleavage stress. There are three principal origins for such weakening of austenite grain boundaries:

(1) Segregation of cohesion reducing solutes and impurities to the austenite grain boundary;

(2) Precipitation of particles (carbides, nitrides) at the austenite grain boundary; 
(3) Hydrogen embrittlement.

Solute atoms and impurities tend to segregate to the austenite grain boundary. In as-quenched martensite, segregation or precipitation can only take place in the austenite phase. Thus, an increased total grain boundary area as a consequence of grain refinement or austenite pancaking should lead to a "geometrical dilution" of segregated elements. Solute hydrogen has a high diffusibility even at low temperatures and can thus segregate to the parent austenite grain boundary after martensite transformation. Hydrogen-induced fracture separates parent austenite grain boundaries by intergranular decohesion at rather low stress intensity [34-38]. Increasing yield strength enhances the sensitivity for hydrogen embrittlement, because it increases the local hydrogen concentration at the tip of a stressed crack or notch and also facilitates reaching the local cohesive stress. Transgranular cracking due to hydrogen embrittlement occurs at higher stress intensities than intergranular decohesion and appears to propagate along planes of maximum shear stress [39]. The fracture appearance resembles that of quasi-cleavage.

Based on the previous considerations, a strategy for optimizing as-quenched martensite basically relies on microstructural refinement, clean steel, and strong parent austenite grain boundaries as schematically indicated in Figure 2. Furthermore, trapping of diffusible hydrogen by nano-sized particles should be considered as a means of counteracting hydrogen induced embrittlement and delayed cracking.

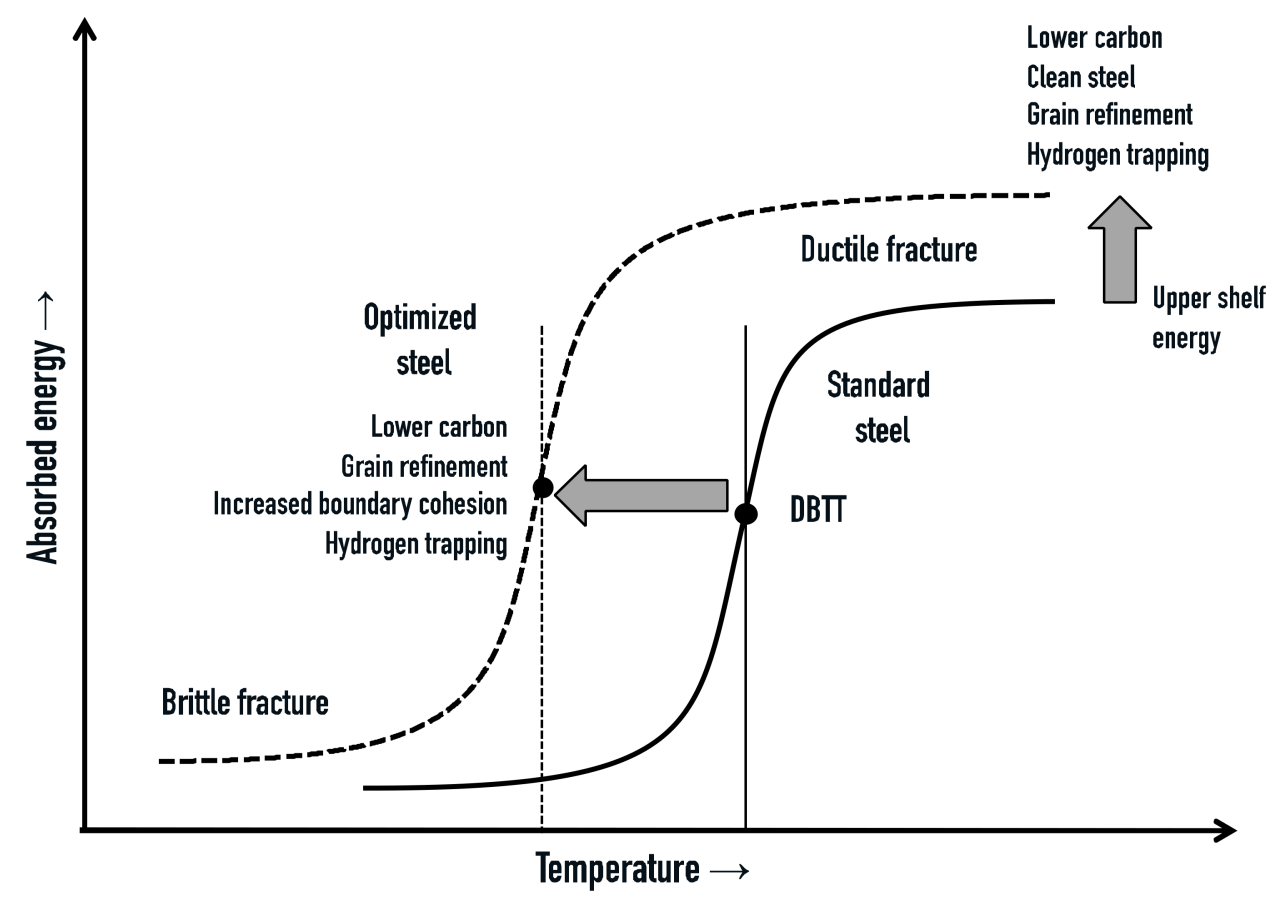

Figure 2. Strategies for optimizing the toughness characteristics of as-quenched martensitic steels.

\section{Alloy Concepts}

Conventional martensitic steels are usually based on a rather simple carbon-manganese alloy concept, often using boron microalloying for boosting hardenability. In such steel, hardness is determined directly by the carbon content $[1,40]$. Figure 3 demonstrates a good linear correlation of measured Vickers hardness (HV) data with the carbon content for steels [41]. Also shown are non-linear relationships between carbon content and strength as proposed by Takaki et al. [42]. The tensile strength well fits the measured hardness data over a wide carbon range if a hardness-to-strength ratio of 1:3 is adjusted. The impact of carbon content on the yield strength is, however, significantly weaker so that the yield-to-tensile ratio decreases with increasing carbon content. However, with increasing hardness 
the toughness of as-quench martensite decreases to rather low values. Therefore, alloyed steel types are often chosen for applications requiring superior toughness.

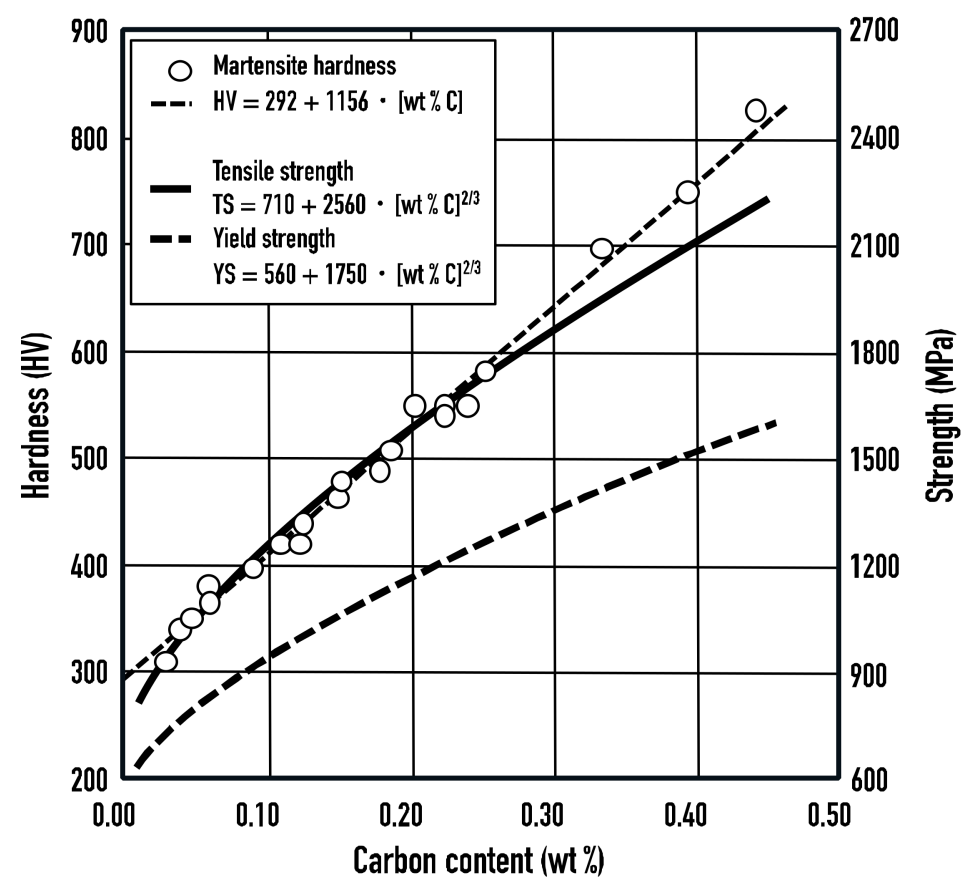

Figure 3. Effect of carbon content on measured hardness (HV0.5) [41] and calculated strength [42] in unalloyed CMn steel with as-quenched martensitic microstructure.

\subsection{Alloy Design for Hardenability}

A fundamental aspect in designing alloy concepts for martensitic steel is hardenability. The alloy design in combination with the applied quenching method must achieve sufficient hardness (strength) over the entire strip or plate thickness. In conventional carbon-manganese steel the hardening depth is limited to a few millimeters only. However, for many applications, much heavier gauges of hardened material are required. Thus, a well-adjusted addition of alloying elements in combination with high cooling rates is needed to achieve a high hardness value in the core of thicker components. Adding alloying elements such as molybdenum, manganese, chromium, copper, and nickel can significantly enhance hardenability. The hardenability effect of molybdenum, manganese, and chromium is related to a reduced diffusivity of carbon when these alloying elements are present in solid solution. The reduced carbon diffusivity strongly retards the formation of ferrite and pearlite. In this respect molybdenum has the strongest hardenability effect. Molybdenum additions of 0.2 to 0.5 mass percent are sufficient for through hardening of heavy gauges under typical quenching conditions. Besides its excellent hardenability effect, molybdenum has the additional benefit of increasing parent austenite grain boundary cohesion, and thus enhancing the resistance against intergranular fracture. This potency of molybdenum has long been noticed empirically by its effect of counteracting tempering embrittlement of martensitic steel. Recent first-principle calculations by Geng et al. [43] confirmed that molybdenum is a strong boundary cohesion enhancer, whereas chromium has no effect in this respect and manganese decreases boundary cohesion.

\subsection{Microalloying in Martensite}

Vanadium microalloying has been standardly applied in martensitic steels for a long time as it provides precipitation strengthening during tempering treatment. Yet, it is rather ineffective in as-quenched martensite due to its good solubility in austenite. Vanadium precipitates providing 
grain size control during re-austenitizing or hydrogen trapping in the as-quenched martensitic microstructure are consequently absent.

Boron is added in very small amounts (10 to $50 \mathrm{ppm}$ ) for its significant hardenability effect. Solute boron strongly segregates to the austenite grain boundary at lower austenite temperature. The high concentration of solute boron in the austenite grain boundary efficiently obstructs the nucleation of ferrite grains below equilibrium transformation temperature, thus preserving metastable austenite down to martensite-start temperature. Since boron tends to precipitate with free nitrogen at lower austenite temperatures, it is usually protected by titanium microalloying [44]. Titanium has a much higher affinity to nitrogen. Over-stoichiometric addition of titanium ( $w \mathrm{t} \% \mathrm{Ti}>3.4 \times \mathrm{wt} \% \mathrm{~N}$ ), however, tends to form primary nitride particles in the liquid steel. These particles are often several micrometers in size and deteriorate toughness $[45,46]$. With regard to achieving an optimum combination of strength and toughness, the Ti/N mass ratio should be adjusted to around 4 . Simultaneously one should aim for the lowest possible nitrogen level, which might require vacuum degassing during steel making.

Historically, the use of niobium microalloying in martensitic steels has not been very common. Its strong grain refining effect in austenite has been considered to reduce hardenability. This concern has meanwhile been discarded [47]. If at all, it is only relevant to simple low-carbon carbon-manganese steels when quenched directly after strong austenite conditioning. Furthermore, it was assumed that there is insufficient solubility of niobium at typical slab reheating temperature considering the relatively high carbon content of typical martensitic grades. Recently, however, niobium microalloying is being increasingly used for improving toughness behavior in as-quenched martensitic strip and plate steels $[26,45,48]$. Applying typical slab soaking practice, the amount of $\mathrm{Nb}$ necessary for deploying its key metallurgical effects, usually up to 0.05 mass percent, can be efficiently brought into solid solution.

\subsection{Alloy Design for Grain Refinement}

According to Section 2 of this paper, refining the "effective" grain size (defined as either parent austenite grains, packets, blocks) is the essential means of improving the properties of as-quenched martensite. Under the conditions of large-scale industrial production, however, only the parent austenite grain size (PAGS) can be efficiently and reproducibly controlled. Boron appears to have an effect on the sub-structure development within the parent austenite grain. Hannula et al. [26] demonstrated that a finer and more homogeneous substructure can be achieved by omitting boron.

Considering the various processing routes for producing martensitic steel the following steps have an influence on the final grain size.

During slab soaking $\left(\mathrm{T}>1100^{\circ} \mathrm{C}\right)$, austenite grains tend to become rather large in size. A successful way of limiting the austenite grain size in this process step is the dispersion of fine TiN particles which are stable at this high temperature. In order to have this pinning effect maximized it is advisable to adjust the titanium addition in a near-stoichiometric ratio to the residual nitrogen in the steel, as mentioned before.

Hot rolling in the recrystallizing regime leads to moderate grain refinement and homogenization. Combining a short inter-pass time (strip mill) and grain boundary drag by solute atoms such as molybdenum and niobium provides additional refinement. The grain morphology is globular.

Finish hot rolling below the recrystallization-stop temperature, so-called thermo-mechanical rolling, causes pancaking of the austenite grain. Niobium is the most effective microalloying element suppressing recrystallization at acceptable finish rolling temperatures. This effect is caused by precipitation of niobium to $\mathrm{NbC}$ particles that pin austenite grain boundaries.

In direct quenched steel either a recrystallized or a pancaked austenite grain structure is converted into martensite, depending on the finish rolling temperature and microalloy concept. In the re-austenitizing quenching route, the hot rolled austenite firstly cools down to ambient temperature, usually transforming into ferrite-pearlite microstructure. This microstructure is finer grained than the original austenite microstructure, particularly after thermo-mechanical rolling. When alloying 
elements like niobium or molybdenum are present as solutes after finish rolling, they will delay the phase transformation to a lower temperature, which additionally refines the ferrite-pearlite microstructure. Depending on the cooling rate after finish rolling, remaining solute niobium will at least partially precipitate during or after phase transformation. These particles are typically in the lower nano-meter size range. Molybdenum, however, stays in solution for typical martensitic steel alloy concepts. Upon re-heating the ferritic-pearlitic microstructure to austenite, any remaining solute niobium precipitates very quickly. The newly formed austenite grains are globular and grow in size depending on the temperature and holding time. Dispersed niobium precipitate particles and, to some extent, solute drag by molybdenum can efficiently impede the austenite grain growth at that stage and thus condition the austenite microstructure before the quenching process.

\section{Examples of Optimized Alloy Concepts and Property Improvement}

Quenchable steel grades with carbon contents from 0.08 to $0.33 \mathrm{wt} \%$ were used as listed in Table 1 , covering a tensile strength range from 1000 to over $2000 \mathrm{MPa}$. The alloy effects of molybdenum and niobium were systematically investigated by varying these elements in the range of 0 to $0.5 \mathrm{wt} \%$ and 0 to $0.08 \mathrm{wt} \%$, respectively. In selected cases the effect of boron and manganese was additionally considered. From a processing point of view, direct quenching was applied after hot rolling. Re-heat quenching was executed after hot as well as cold rolling. The study initially analyzes the effect of alloy concept and processing conditions on the microstructure. Subsequently, microstructural influences on the steel properties are being verified and discussed in the background provided in Section 2 of this paper.

Table 1. Chemical composition in wt \% of hot rolled (HR) and cold rolled (CR) direct quenched (DQ) and re-heat quenched (RHQ) steels analyzed in this study.

\begin{tabular}{|c|c|c|c|c|c|c|c|c|c|}
\hline Material & $\mathrm{C}$ & $\mathrm{Si}$ & Mn & $\mathrm{Cr}$ & $\mathrm{Ni}$ & $\mathrm{Ti}$ & B & Mo & $\mathrm{Nb}$ \\
\hline \multicolumn{10}{|l|}{ DQ grades } \\
\hline $0.08 \%$ C HR & 0.08 & 0.2 & 1.8 & 1.1 & - & 0.02 & 0 or 0.0025 & 0.15 & var. $0-0.05$ \\
\hline $0.16 \%$ C HR & 0.16 & 0.2 & 1.1 & 0.5 & 0.5 & - & - & var. $0-0.5$ & var. $0-0.04$ \\
\hline \multicolumn{10}{|l|}{ RHQ grades } \\
\hline HB450 HR & 0.18 & 0.2 & 1.2 & 0.2 & - & 0.03 & 0.0020 & 0.25 & 0.03 \\
\hline 22MnB5 HR & 0.22 & 0.2 & 1.2 & 0.2 & - & 0.03 & 0.0025 & var. $0-0.15$ & 0.05 \\
\hline 16MnB5 CR & 0.16 & 0.4 & 2.3 & - & - & 0.03 & 0.0025 & - & var. $0-0.08$ \\
\hline 22MnB5 CR & 0.23 & 0.3 & 1.2 & 0.2 & - & 0.03 & 0.0025 & - & var. $0-0.08$ \\
\hline 32MnB5 CR & 0.33 & 0.1 & 1.2 or 2.5 & - & - & 0.02 & 0.0020 & var. $0-0.5$ & var. $0-0.05$ \\
\hline
\end{tabular}

\subsection{Microstructure of Low-Carbon Direct Quenching Steel}

In a series of $0.08 \% \mathrm{C}-1.8 \% \mathrm{Mn}-1.1 \% \mathrm{Cr}-0.15 \%$ Mo steels with boron microalloying, the niobium content was systematically varied from zero to $0.05 \% \mathrm{Nb}$. The alloy containing $0.02 \% \mathrm{Nb}$ was also produced without boron microalloying. All steels were solution treated at $1250{ }^{\circ} \mathrm{C}$ and hot rolled in six passes to $6 \mathrm{~mm}$ gauge as described by Hannula et al. [26]. Two finish rolling temperatures, namely 920 and $820^{\circ} \mathrm{C}$, have been applied in individual rolling schedules, the latter leading to stronger austenite conditioning. The finish rolled strips were then directly quenched to room temperature using water providing a cooling rate of around $90^{\circ} \mathrm{C} / \mathrm{s}$. All steels were fully hardenable, except the boron-free alloy which was finish rolled at $920^{\circ} \mathrm{C}$. Analyzing the parent austenite grain morphology, only the niobium-free alloy finish rolled at $920^{\circ} \mathrm{C}$ shows a nearly globular grain shape. However, the same alloy finish rolled at $820^{\circ} \mathrm{C}$ is clearly pancaked. In the absence of niobium microalloying, this can be due to solute drag effects acting on the austenite grain boundary caused by segregated molybdenum and boron. All niobium microalloyed steels exhibit even more pronounced austenite pancaking under both finishing temperatures. Austenite pancake thicknesses are in the range of 5 
to $6 \mu \mathrm{m}$ and 8 to $10 \mu \mathrm{m}$ for the lower and higher finishing temperatures, respectively. A synergy between niobium and boron is noticed in the sense that boron further suppresses recrystallization above the level already provided by niobium alone. Based on EBSD analysis [26], effective grain and lath sizes were determined as equivalent circle diameter (ECD) values with low-angle $\left(3-15^{\circ}\right)$ and high-angle boundary $\left(>15^{\circ}\right)$ misorientation, respectively. As proposed before, the effective grain size in the as-quenched material is determined by the austenite pancake thickness. Figure 4 correlates the effective grain size with the parent austenite pancake thickness. Higher niobium addition and lower finishing temperatures result in more severe pancaking and hence finer effective grain size. Wang et al. [21] demonstrated a similar behavior for martensite having a globular parent austenite grain morphology.

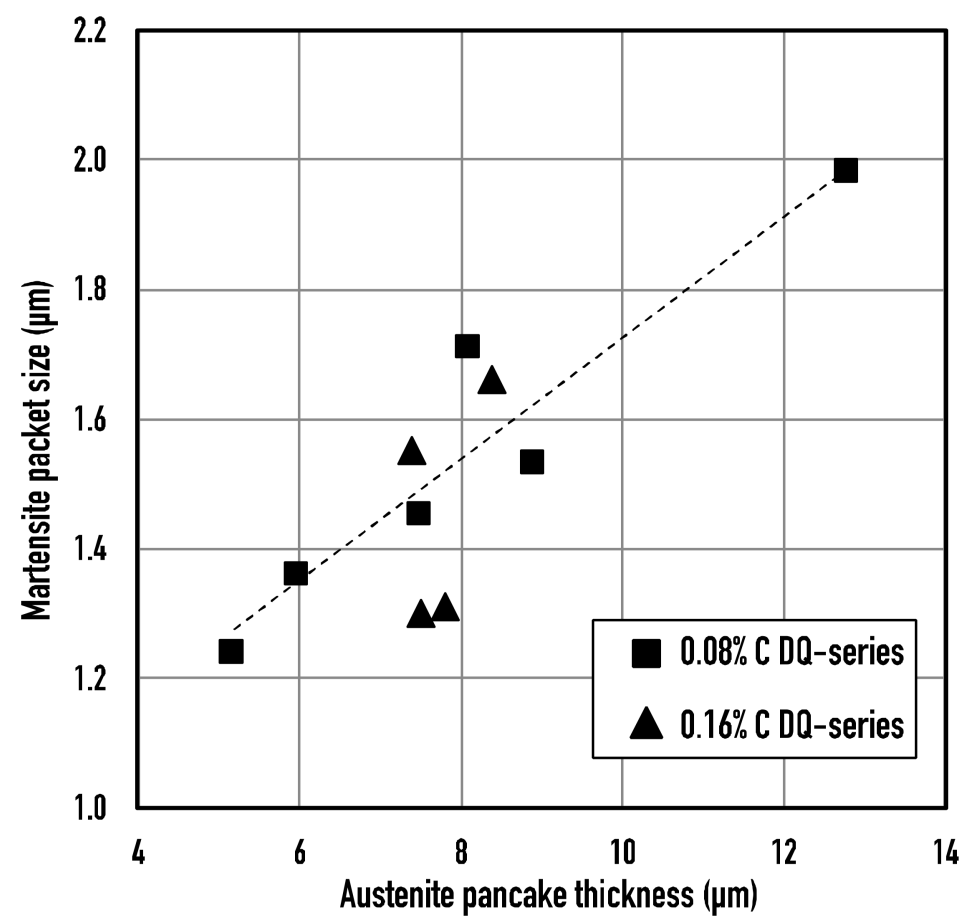

Figure 4. Correlation of martensite packet size with the parent austenite pancake thickness in direct quenched steel after non-recrystallizing hot rolling.

In a series of $0.16 \% \mathrm{C}-1.1 \% \mathrm{Mn}-0.5 \% \mathrm{Cr}-0.5 \% \mathrm{Ni}$ steels, the molybdenum content was varied from zero to $0.5 \%$ Mo. The reheating and rolling procedure was like that in the previous series of lower carbon steels; $900{ }^{\circ} \mathrm{C}$ was taken as finishing temperature for this series. Quenching was done using water directly after finish rolling resulting in fully martensitic microstructure. The parent austenite grain structure is shown in Figure 5. The Mo-free alloy exhibits globular shaped austenite grains, whereas adding $0.25 \%$ Mo results in pancaking under the same rolling conditions. Solute drag effects provided by molybdenum obstruct full recrystallization. With a further increased molybdenum content $(0.5 \% \mathrm{Mo})$, austenite pancaking is marginally more pronounced. Adding however $0.04 \% \mathrm{Nb}$ to the $0.25 \%$ Mo steel leads to significantly thinner austenite pancake thickness. The correlation of the effective grain size with the parent austenite thickness is shown in Figure 4. 


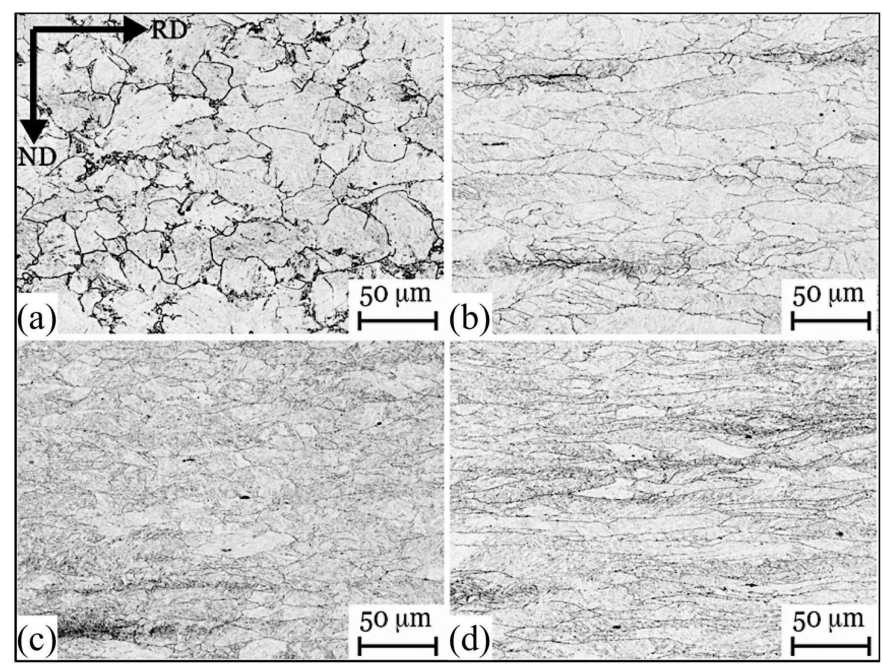

Figure 5. Parent austenite grain morphology of (a) $0 \% \mathrm{Mo}$; (b) $0.25 \% \mathrm{Mo}$; (c) $0.5 \% \mathrm{Mo}$; (d) $0.25 \% \mathrm{Mo}+$ $0.04 \% \mathrm{Nb}$ direct quenched steel (finish rolling temperature of $900{ }^{\circ} \mathrm{C}$ ).

\subsection{Microstructure of Re-Austenitize Quenching Steel}

For this processing route, a series of medium carbon steels typically used for the automotive press hardening process is analyzed. These steels contain $0.20-0.35 \% \mathrm{C}, 1.0-1.8 \% \mathrm{Mn}, 0-0.50 \% \mathrm{Cr}$ boron microalloying (20-40 ppm), molybdenum additions between zero and $0.25 \%$ Mo and niobium additions between zero and $0.08 \% \mathrm{Nb}$. Usually, there is no explicit austenite conditioning foreseen in the hot-rolling schedule of such steels. However, it is possible that for some of the niobium or molybdenum added variants a significant degree of austenite pancaking can be expected. Figure 6 shows microstructures of 22MnB5 with niobium $(0.05 \% \mathrm{Nb})$ as well as combined niobium-molybdenum $(0.05 \% \mathrm{Nb}+0.15 \% \mathrm{Mo})$ addition in the as-hot-rolled state (6 mm gauge). The ferritic-pearlitic microstructure indicates that the austenite indeed was pancaked (FRT: $850{ }^{\circ} \mathrm{C}$ ). However, the transformed microstructure appears much finer in the $\mathrm{Nb}+\mathrm{Mo}$ added steel. This can be due to a retarded transformation after finish rolling by solute molybdenum resulting in a bainitic microstructure. Parent austenite morphology analysis indicated that the $\mathrm{Nb}$-only and $\mathrm{Nb}-\mathrm{Mo}$ steel both had austenite pancake thicknesses between 5 and $6 \mu \mathrm{m}$. Figure 7 shows the pancake structure of the $\mathrm{Nb}-\mathrm{Mo}$ steel. The pancake structure is erased and replaced by a globular austenite morphology after re-austenitizing $\left(900^{\circ} \mathrm{C}\right.$ for $900 \mathrm{~s}$ ). The average recrystallized parent austenite sizes are around $7 \mu \mathrm{m}$ for both the $\mathrm{Nb}$-only and $\mathrm{Nb}+\mathrm{Mo}$ steel. Detailed microstructural analysis using an EBSD-based technique described by Hannula et al. [26] revealed that the effective grain size in these steels after re-austenitizing quenching is in the order of $1.5 \mu \mathrm{m}$. Accordingly, strength and toughness properties differ only marginally between the two steels.
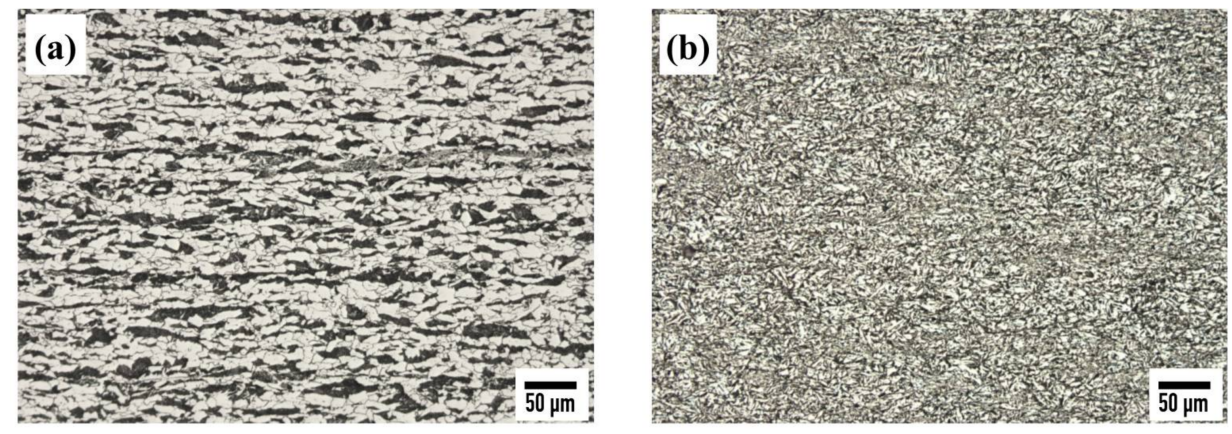

Figure 6. As-hot-rolled microstructure of $22 \mathrm{MnB} 5$ steel alloyed with $\mathrm{Nb}(\mathbf{a})$ and $\mathrm{Mo}+\mathrm{Nb}(\mathbf{b})$. 

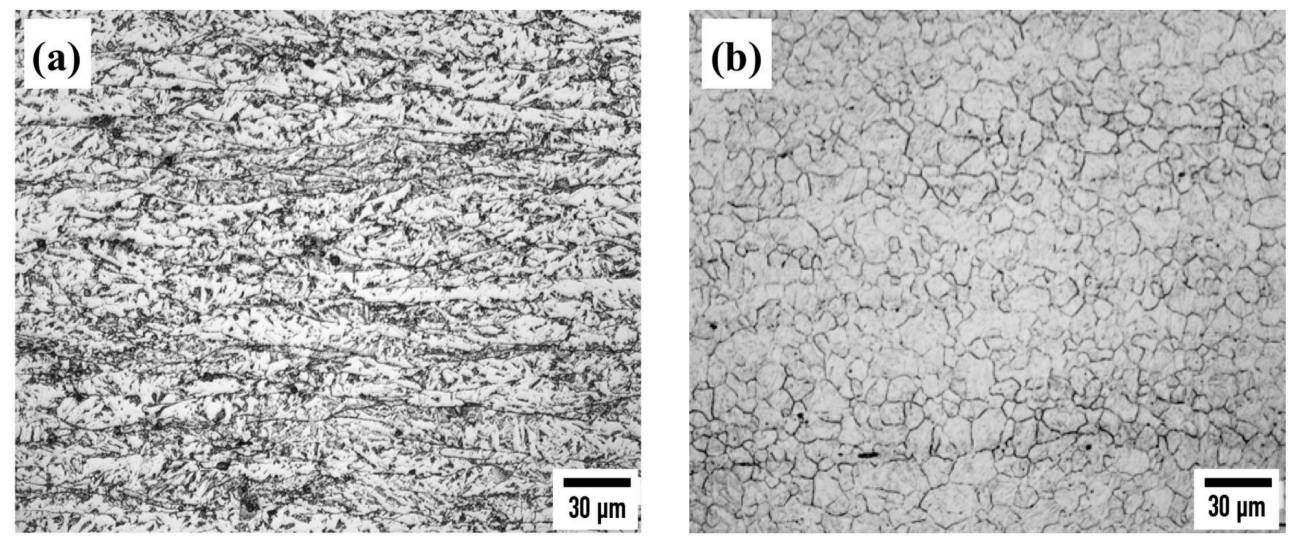

Figure 7. Parent austenite grain morphology of $\mathrm{Mo}+\mathrm{Nb}$ alloyed $22 \mathrm{MnB} 5$ steel after hot rolling (a) and after re-austenitizing quenching $(\mathbf{b})$.

The size of the recrystallized austenite grain with globular shape depends not only on the as-hot-rolled austenite grain size having globular or pancaked shape, but also on the heating conditions of the re-austenitizing treatment. Higher temperature or longer austenitizing duration impose growth of the recrystallized austenite grains so that these are usually bigger than the original ones (Figure 8). Therefore, it is of key importance to restrict this austenite growth. This can be achieved by optimizing the reheating schedule (low temperature, short time). However, under industrial circumstances over-heating cannot be always excluded and for process robustness one would likely not operate at the lower limit conditions. For that reason, it is favorable to obstruct austenite grain coarsening using solute drag or, more powerfully, by particle pinning effects.

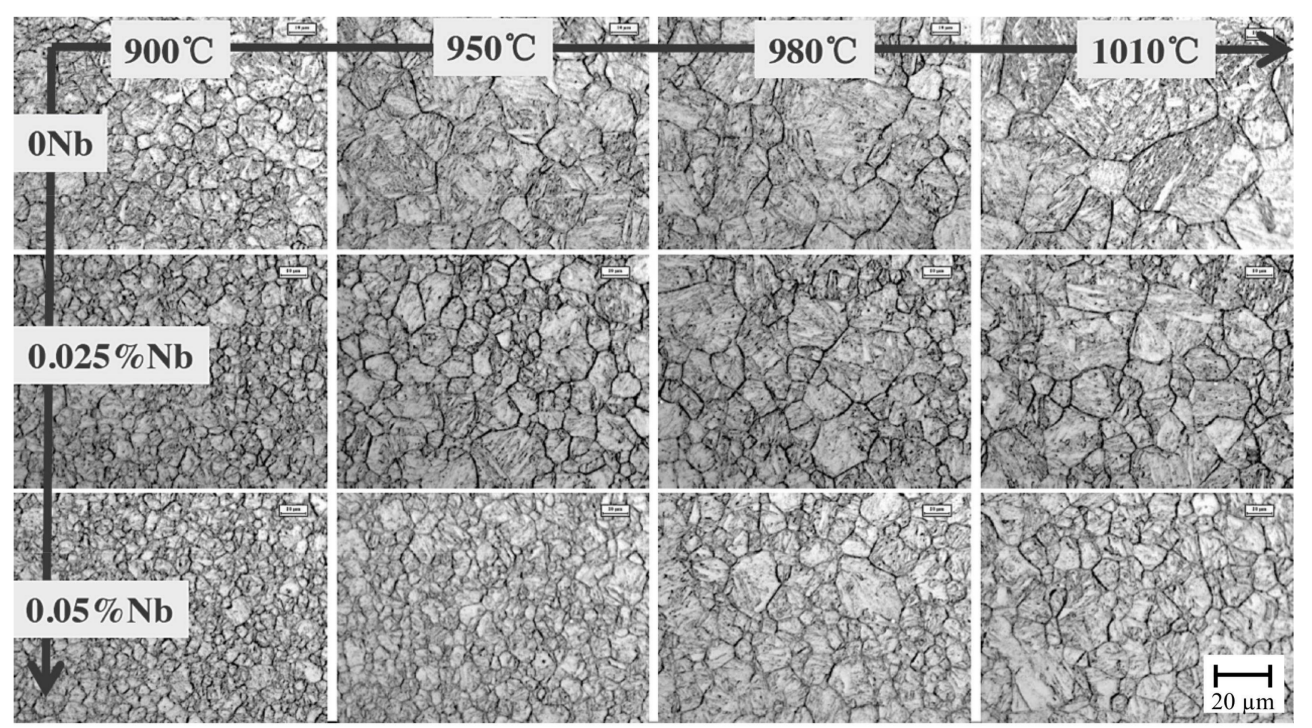

Figure 8. Effect of niobium microalloy content (rows) on parent austenite grain morphology in re-austenitized quenched 22MnB5 steel for various reheating temperatures (columns) for a treatment duration of $300 \mathrm{~s}$.

Niobium carbide precipitate particles are thermodynamically stable at typical re-austenitizing temperatures. Hence, efficient grain boundary pinning can be expected when such particles are present in sufficient quantity and with a homogenous spatial distribution. In order to demonstrate this effect, $22 \mathrm{MnB} 5$ steel was alloyed with various additions of niobium. The as-hot-rolled ferritic-pearlitic material was further cold rolled to $1.5 \mathrm{~mm}$ final gauge. Subsequently, austenitizing treatments were 
done at temperatures between 900 and $1010{ }^{\circ} \mathrm{C}$, each for $300 \mathrm{~s}$. The parent austenite structure was developed after quenching as shown in Figure 8. The effect of $\mathrm{NbC}$ particles restricting austenite growth is evident at all re-heating temperatures. The higher niobium $(0.05 \% \mathrm{Nb})$ addition provides a stronger growth-inhibiting effect, implying that the number of particles must be bigger with a more homogeneous spatial distribution. The addition of $0.05 \% \mathrm{Nb}$ appears to be an optimum amount in this steel as higher niobium addition brings no further advantage (Figure 9). It is reasonable to conclude that more than $0.05 \% \mathrm{Nb}$ cannot be brought into solution in this alloy during initial slab reheating. Only the dissolved niobium can precipitate to a particle size range providing efficient grain boundary pinning. The optimum niobium addition particularly shows its advantage at higher re-austenitizing temperatures (Figure 8). It allows a combination of a fine final parent austenite grain size with a robust re-austenitizing processing window.

(a)

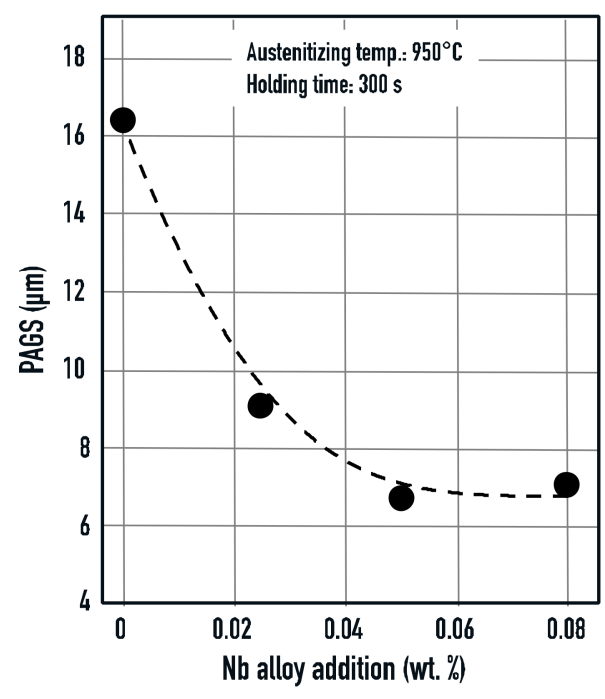

(b)

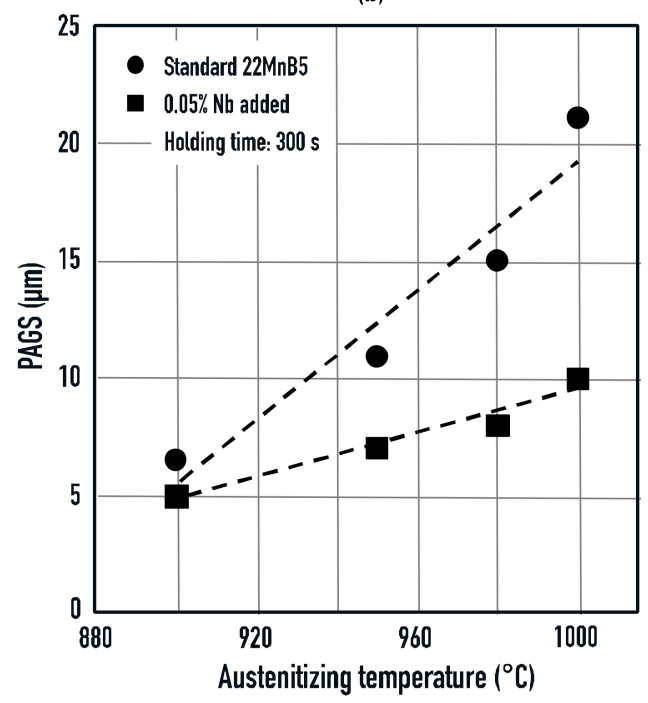

Figure 9. (a) Effect of niobium on parent austenite grain size control under typical re-austenitizing conditions used in the automotive press hardening process; (b) demonstration of robustness against overheating for a niobium alloyed variant.

\subsection{Effective Grain Size and Strength}

Strength data measured on various direct quenched and re-austenitized quenched steels are plotted against the inverse square root of the parent austenite grain size in Figure 10. The data sets show good linear correlation as expected by the Hall-Petch relationship (Equation (1)). The niobium microalloyed steel grades show yield strength Hall-Petch coefficients of similar magnitude, and irrespective of the actual strength level (carbon content). The Hall-Petch coefficients for the tensile strength are also similar but somewhat smaller in magnitude. The strength of the niobium-free steel with variable molybdenum content shows significantly larger Hall-Petch coefficients. The tensile strength has a larger Hall-Petch coefficient than the yield strength in these steels. 


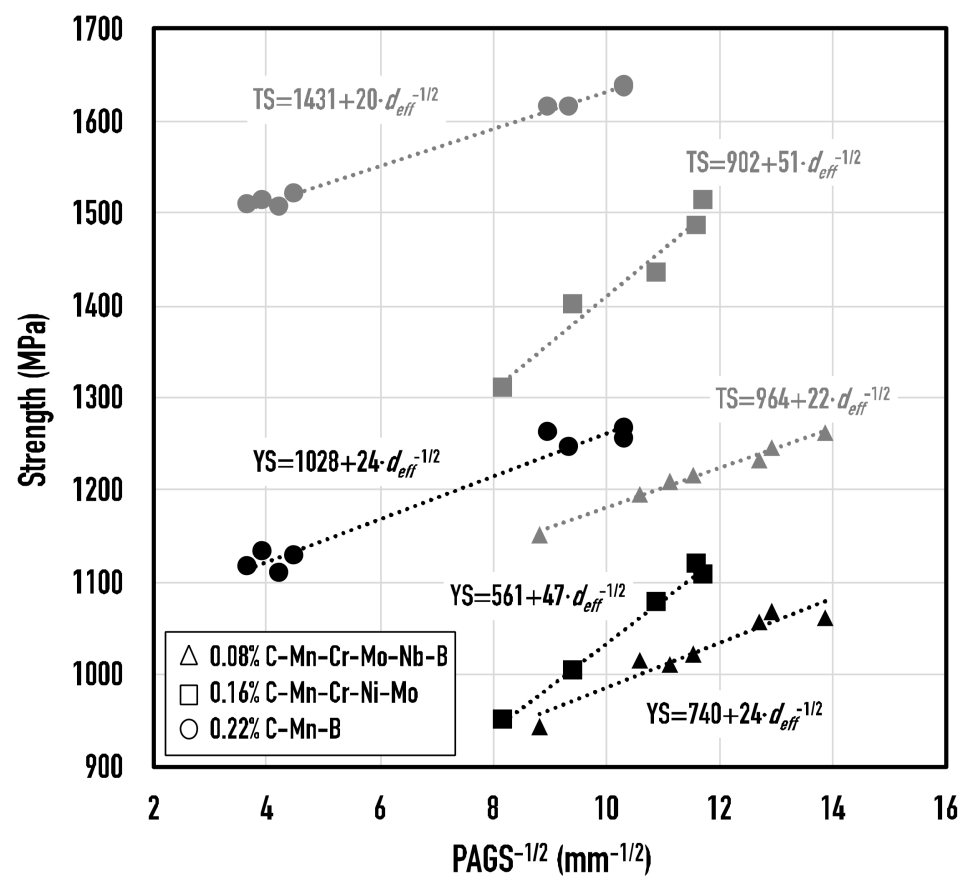

Figure 10. Hall-Petch type plot indicating the effect of parent austenite grain size (pancake thickness for direct quenched steels) on yield (black symbol) and tensile (grey symbol) strength.

\subsection{Effective Grain Size and Toughness}

Using the Hall-Petch coefficients for yield strength of around $24 \mathrm{~N} \cdot \mathrm{mm}^{-3 / 2}$ for the Mn-B steel types and $47 \mathrm{~N} \cdot \mathrm{mm}^{-3 / 2}$ for the Mo steel types, and the previously quoted Hall-Petch coefficient of $160 \mathrm{~N} \cdot \mathrm{mm}^{-3 / 2}$ for the fracture stress in martensite in the Yoffee approach, it can be expected that grain refinement should clearly lower the ductile-to-brittle transition temperature in these steels.

Verification of this assumption was done using selected samples of the direct quenching steels. Toughness was measured using Charpy V-notch specimens. Due to the thickness of the rolled products $(6 \mathrm{~mm})$, sub-size samples $\left(5 \times 10 \times 55 \mathrm{~mm}^{3}\right)$ had to be used. From the Mo-series $(0.16 \% \mathrm{C}-1.1 \%$ $\mathrm{Mn}-0.5 \% \mathrm{Cr}-0.5 \% \mathrm{Ni}-\mathrm{Mo}$ variable), four samples were taken having a fully martensitic microstructure, that is, without detectable traces of other phases. Charpy tests were performed over the temperature range from $20^{\circ} \mathrm{C}$ down to $-150{ }^{\circ} \mathrm{C}$. The upper shelf energy is always higher in the rolling direction (around $50 \mathrm{~J}$ ) than in the transverse direction (around $30 \mathrm{~J}$ ) reflecting the anisotropy present in direct quenched steels. The transition temperatures are shown Figure 11a for the test done in rolling direction taking $28 \mathrm{~J}$ as the defining criterion. It is obvious that samples with finer PAGS have a lower transition temperature and the data correlate according to a Hall-Petch-type relationship. The Hall-Petch coefficient according to (Equation (3)) is for these steels approximately $12 \mathrm{~K} \cdot \mathrm{mm}^{1 / 2}$. These data become more meaningful when plotting the transition temperature versus the room temperature yield strength as in Figure 11b. It is obvious that despite a significant strength increase (170 MPa) the transition temperature is drastically lowered $(-40 \mathrm{~K})$. Also these data are in a linear relationship, since both quantities are originally linearly related to the square root of the PAGS.

The toughness behavior of the $\mathrm{Nb}-\mathrm{B}$ series of steels $(0.08 \% \mathrm{C}-1.8 \% \mathrm{Mn}-1.1 \% \mathrm{Cr}-0.15 \% \mathrm{Mo}-\mathrm{Nb}-\mathrm{Ti}$, B variable) was in detail discussed by Hannula et al. [26] so that here only the most relevant observations are resumed. In the rolling direction, the upper shelf energy is between 40 and $50 \mathrm{~J}$ and thus somewhat lower than that observed for the Mo-series. Likewise, the lower shelf energy is below that seen in the Mo-series. The upper shelf energy in the transverse direction is much lower, reflecting the anisotropy present in direct quenched steels (Figure 12). The upper shelf energy in these steels decreases with the degree of austenite conditioning. A significant difference in the 
ductile-to-brittle transition behavior is observed between the boron-containing and the boron-free alloys, the latter performing much better. Hannula et al. [26] explained this result by a finer grained and more homogeneous microstructure of the boron-free steel. Microstructural refinement is generally more pronounced at lower finish rolling temperatures, yet so is the difference in ductile-to-brittle transition temperature. The fact that the microstructural inhomogeneity appears to be stronger at lower finish rolling temperature can be due to a retarding influence of boron on the recrystallization behavior in addition, and likely in synergy to that of niobium. Consequently, thorough homogenization of the austenite structure by multiple recrystallization at higher temperatures may be more severely obstructed. Mixed parent austenite grain size also results in enhanced quench distortion, which is due to the influence of austenite grain size on the martensite transformation temperature and accommodating residual stress between the grains [49].

(a)

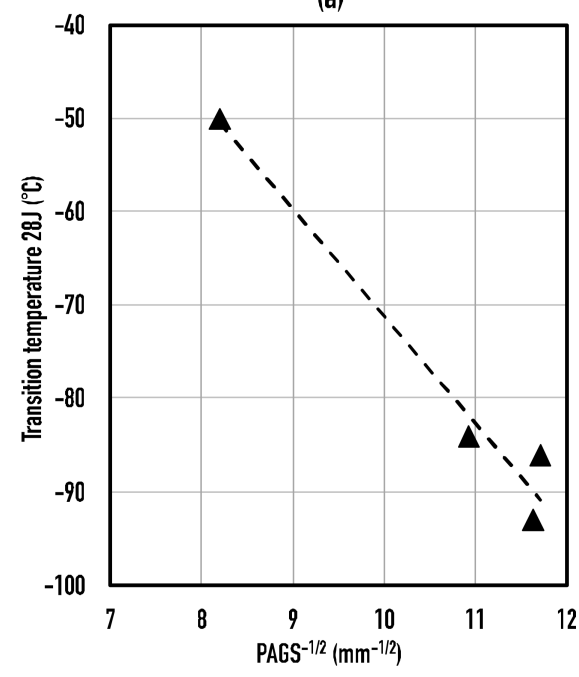

(b)

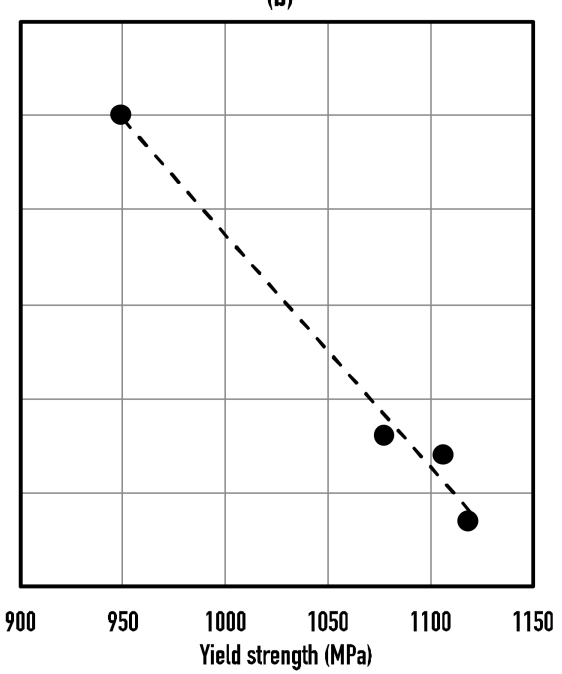

Figure 11. (a) Hall-Petch type plot indicating the effect of parent austenite grain size in direct quenched $0.16 \%$ C- $1.1 \%$ Mn- $0.5 \%$ Cr- $0.5 \%$ Ni-Mo steels on ductile-to-brittle transition temperature (28 J criterion); (b) correlation between yield strength and ductile-to-brittle transition temperature for the same steels indicating simultaneous improvement of both properties.

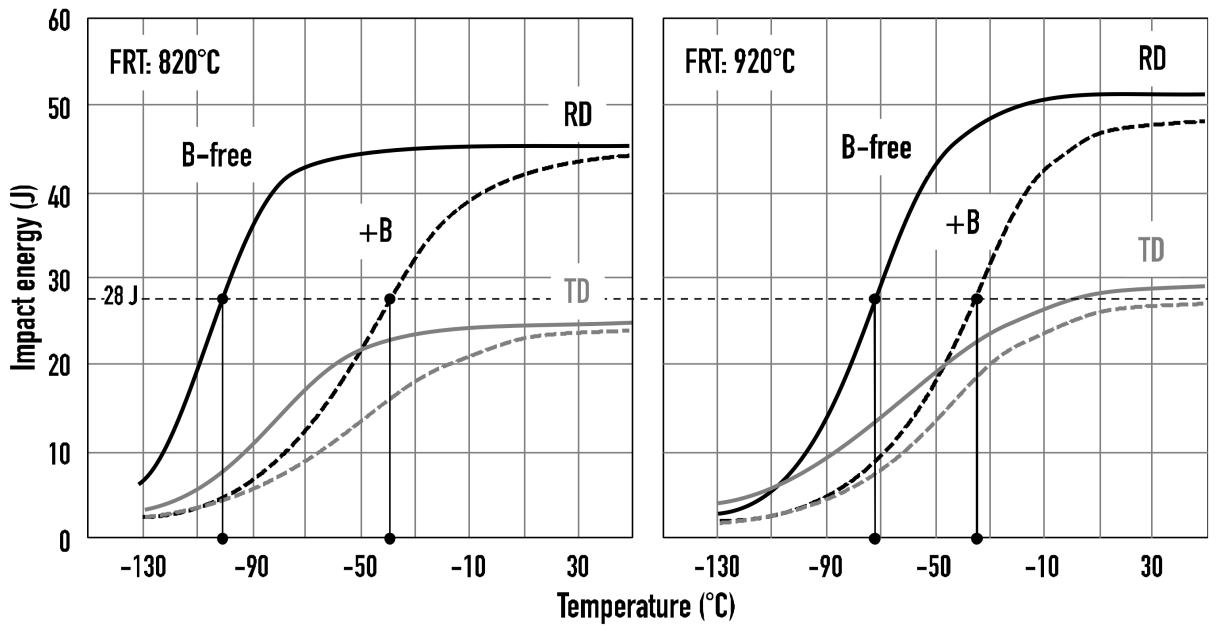

Figure 12. Anisotropy (black curve: rolling direction (RD), gray curve: transverse direction (TD)) of ductile-to-brittle transition behavior of direct quenched $0.08 \% \mathrm{C}-1.8 \% \mathrm{Mn}-1.1 \% \mathrm{Cr}-0.15 \% \mathrm{Mo}-\mathrm{Nb}$ steel and influence of boron addition (solid line B-free, dashed line B-added) at two finish-rolling temperatures (FRT). 
In re-austenitized-quenched steel the parent austenite microstructure is rather isotropic as a result of the normalization caused by the phase transformations occurring prior to quenching. In these steels, refinement of the parent austenite grain size increases the upper-shelf energy as shown in Figure 13 (data refer to the steels shown in Figure 9a). Another example (Figure 14) demonstrates the improvement that can be achieved by niobium microalloying to HB450 abrasion resistant steel plate. Due to the relatively low slab reheating temperature practiced in plate mills, niobium solubility limits the addition to a maximum of $0.03 \mathrm{wt} \% \mathrm{Nb}$. This amount is sufficient for restricting austenite coarsening at a re-austenitizing temperature of $900{ }^{\circ} \mathrm{C}$ as compared to a niobium-free alloy. It achieved refinement from an average parent austenite grain size of $18 \mu \mathrm{m}$ in the $\mathrm{Nb}$-free to $12 \mu \mathrm{m}$ in the $0.03 \%$ $\mathrm{Nb}$-added steel as well as a more homogeneous size distribution in the latter. This optimization results in a significant increase in upper-shelf energy by approximately $30 \mathrm{~J}$ and a reduction of ductile-to-brittle transition temperature by around $20^{\circ} \mathrm{C}$ for the niobium added steel. Similar improvements using the same metallurgical approach were reported earlier by Kern et al. [46] and Ishikawa et al. [48] for optimizing toughness of wear plate in industrial production.

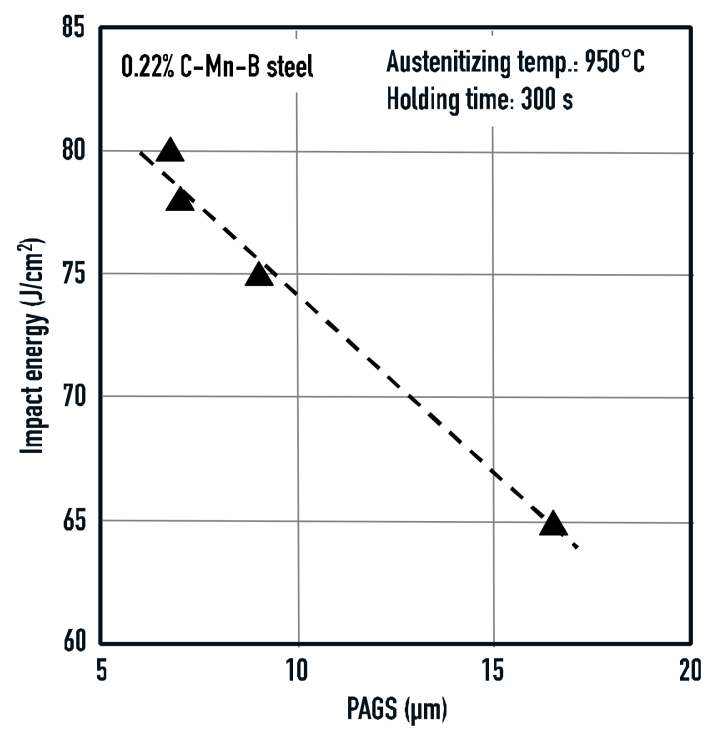

Figure 13. Effect of parent austenite grain size on upper-shelf energy for re-austenitized quenched $22 \mathrm{MnB} 5$ steel tested at ambient temperature $\left(20^{\circ} \mathrm{C}\right)$.

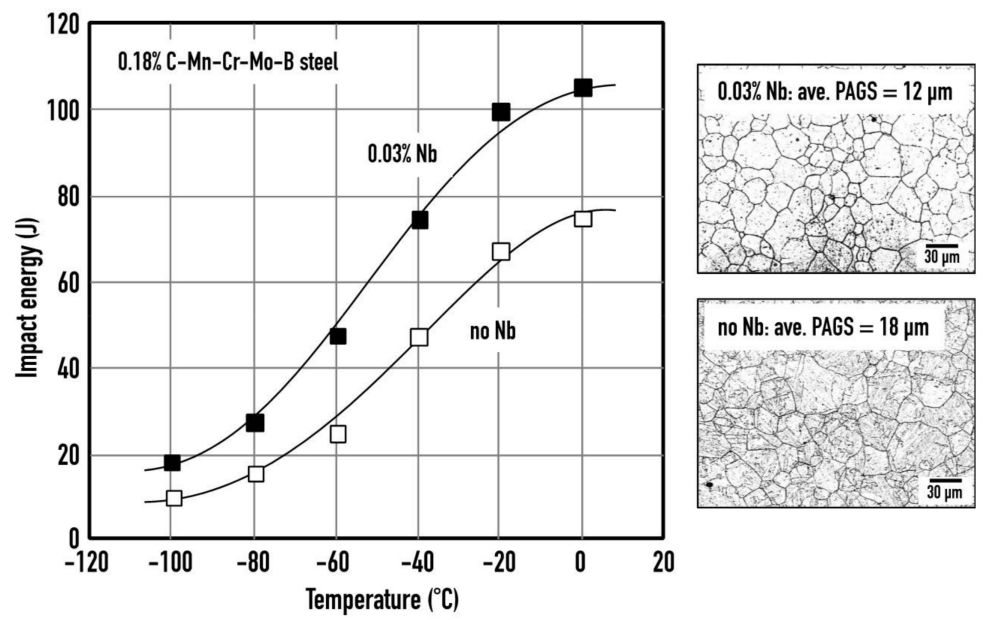

Figure 14. Influence of parent austenite grain refinement on ductile-to-brittle transition curves of HB450 abrasion resistant plate steel $(0.18 \%$ C-Mn-Cr-Mo-B) produced by re-austenitizing quenching. 


\section{Optimization against Hydrogen Embrittlement}

The presence of hydrogen in steel can severely limit the performance of high strength steels as detailed in a concise review by Gangloff [50]. Two types of non-ductile fracture can be observed in martensitic steel when hydrogen is present in small amounts. Intergranular fracture (Figure 15) is seen when hydrogen aggregates at parent austenite grain boundaries, weakening the grain boundary cohesion so much that failure occurs at a stress level far below the yield strength. Already the presence of around $0.4 \mathrm{ppm}$ diffusible hydrogen is sufficient to cause intergranular fracture if microstructural optimization is not foreseen. Means of optimization are refinement of the parent austenite grain size, dispersion of particles with hydrogen trapping capacity, and metallurgical reinforcement of parent austenite grain boundaries. Depending on the efficiency of these means as well as the actual hydrogen content the fracture surface becomes of quasi-cleavage type (Figure 15) or even dimple type.

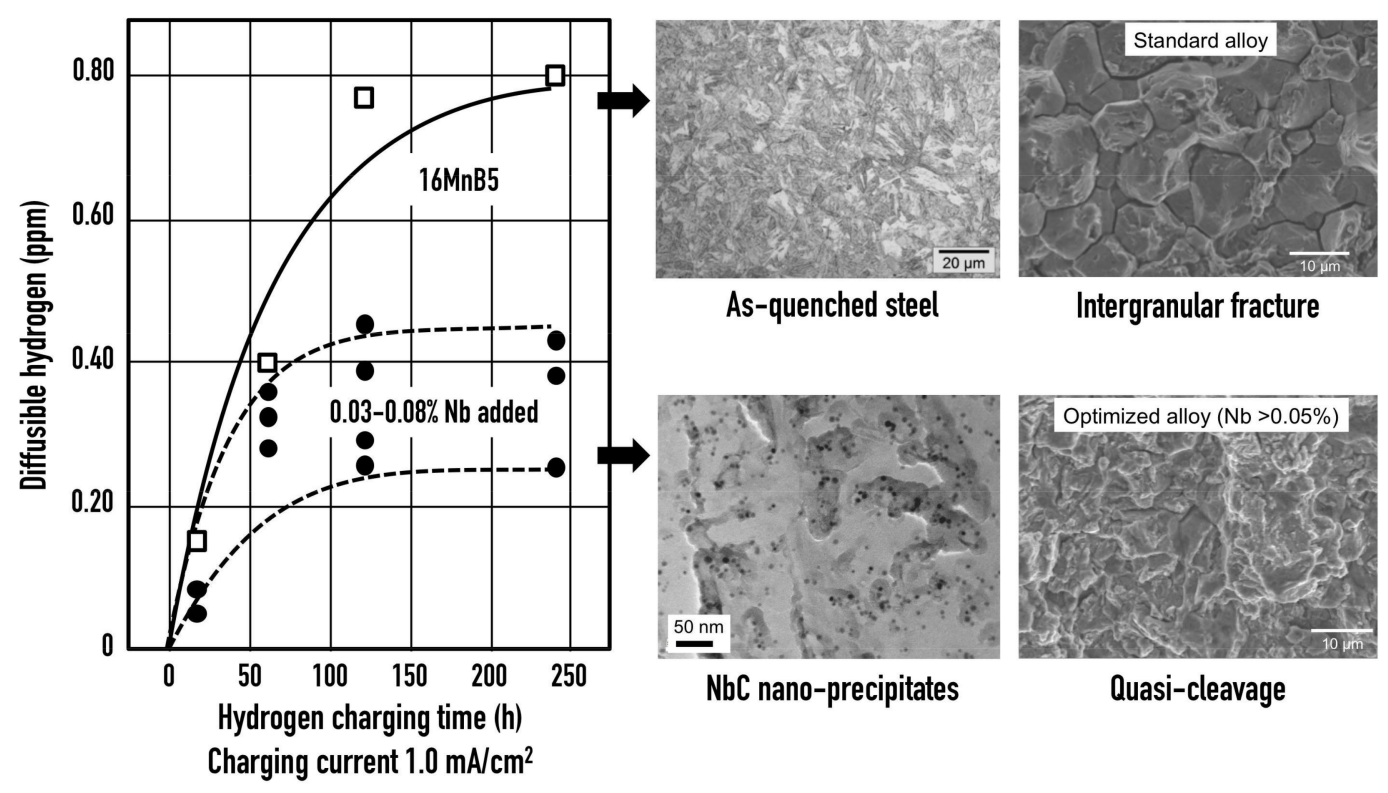

Figure 15. Amount of diffusible hydrogen in $16 \mathrm{MnB} 5$ measured by thermal desorption analysis (TDA) and influence of niobium microalloying; microstructural features and fracture surface after constant load testing.

\subsection{Effect of Grain Refinement}

For screening the hydrogen sensitivity of martensitic steels, in this case automotive press hardening sheet steels of $1.4 \mathrm{~mm}$ gauge, double notched tensile samples were immersed in $20 \%$ ammonium thiocyanate solution under constant load conditions with an acting stress of $1000 \mathrm{MPa}$ at the notch [51]. Failure at this stress level is not instant but occurs with a certain time delay (time-to-fracture). Figure 16 indicates that the time to fracture becomes much shorter when the tensile strength level being $1500 \mathrm{MPa}$ in grade 22MnB5 is raised to $2000 \mathrm{MPa}$ in grade 32MnB5. These steel grades are standard alloys containing two different levels of carbon $(0.22 \%$ and $0.32 \%)$, manganese $(1.2 \mathrm{wt} \%)$, as well as boron (30 ppm) for hardenability. In a variant, the manganese level was set higher $(2.5 \mathrm{wt} \%)$. In this variant, time-to-fracture becomes notably shorter indicating that manganese increases the sensitivity for hydrogen embrittlement and should therefore be kept as low as possible.

In order to show the influence of the parent austenite grain size and to exclude that of other effects such as hydrogen trapping, the PAGS of the base steels was varied between 4 and $60 \mu \mathrm{m}$ by using different re-austenitizing temperatures. In all steels, smaller parent austenite grain size results in clearly longer time-to-fracture. Momotani et al. [52] demonstrated by hydrogen micro-print technique that hydrogen, which was originally distributed evenly within the matrix, aggregates on the parent 
austenite grain boundaries upon application of stress. Since this mechanism is diffusion controlled, it requires a certain time for hydrogen to redistribute. Substantial concentration of hydrogen at the parent austenite grain boundary leads to intergranular fracture. Reducing the parent austenite grain size has two effects with respect to that mechanism:

(1) The average diffusion distance from the grain bulk to the parent austenite grain boundary becomes shorter, hence reducing the time delay for hydrogen to aggregate on the boundary.

(2) The total grain boundary area becomes substantially larger so that for a given amount of hydrogen its average concentration per unit grain boundary area will be lower.

Similar delayed cracking tests by other researchers [53-55] applying constant load conditions to $22 \mathrm{MnB} 5$ under hydrogen charging conditions revealed that the failure stress after severe grain boundary embrittlement by hydrogen is only in the range of 400-600 MPa. This range is much below the yield strength of such steel (about $1100 \mathrm{MPa}$ ) and accordingly, ductile failure mechanisms are prevented. Higher addition of manganese reduces grain boundary cohesion [43] enhancing the negative effect of hydrogen embrittlement, whereas molybdenum has the opposite effect of counteracting hydrogen embrittlement.

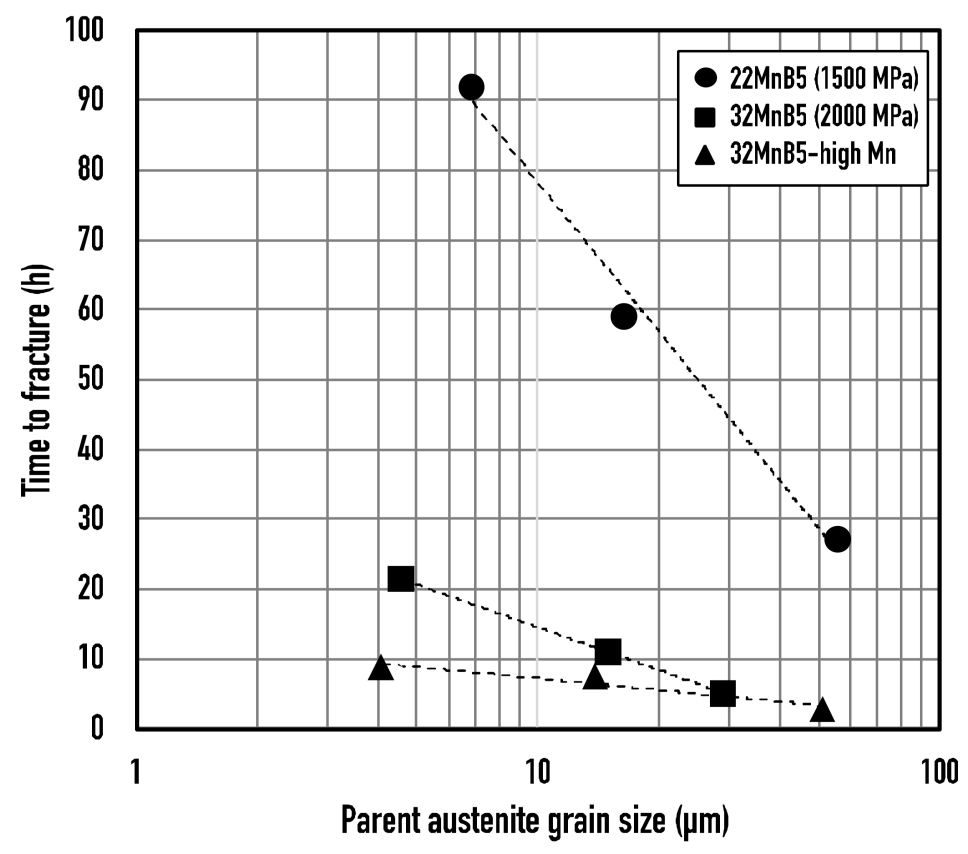

Figure 16. Delayed fracture behavior of as-quenched manganese-boron steels (without niobium microalloying) as a function of parent austenite grain size modified by variation of the re-austenitizing temperature.

\subsection{Effect of Hydrogen Trapping by Precipitate Particles}

Microalloy carbides are known to act as hydrogen traps in martensitic steels [50,56]. Wei et al. [57] identified that the hydrogen trapping potential depends on the microalloying element forming the carbide according to the following ranking: $\mathrm{NbC}>\mathrm{TiC}>\mathrm{VC}$. Without going into the details of trapping mechanisms in this paper, evidence is presented that hydrogen trapping by $\mathrm{NbC}$ precipitates works efficiently for optimizing as-quenched martensitic steel and addition of molybdenum provides further improvement.

The effect of niobium was investigated in the same 22MnB5 steels [55], which were already presented in Figure 9a. Using hydrogen permeation tests, the hydrogen diffusivity was measured for different niobium additions (Figure 17a). The hydrogen diffusion coefficient is lowered by the addition 
of niobium reaching a minimum when $0.05 \% \mathrm{Nb}$ is added. Niobium present in this steel completely precipitates after a re-austenitizing quenching treatment. Thorough transmission elcectron microscopy (TEM) precipitate size distribution analysis (Figure 17b) revealed that these precipitates have diameters in the range of up to 40 nanometers. Larger precipitate sizes are likely formed early in the process chain, for example, during hot rolling. The difference between the three niobium addition levels is that for $0.05 \% \mathrm{Nb}$ the highest fraction of ultra-fine particles of sizes below 5 nanometers is observed. This size distribution consequently results in an increased particle density and high particle surface-to-volume ratio. It reasonable to assume that these features enhance the interaction of hydrogen with particles, leading to more efficient trapping. If $\mathrm{NbC}$ particles act as irreversible trap, the amount of diffusible hydrogen responsible for causing damage in the steel will be effectively lowered (Figure 15).

(a)

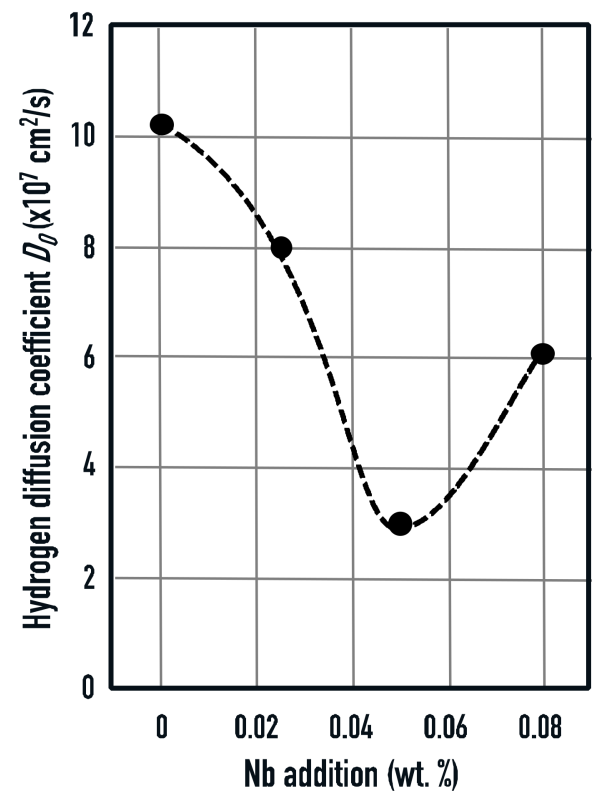

(b)

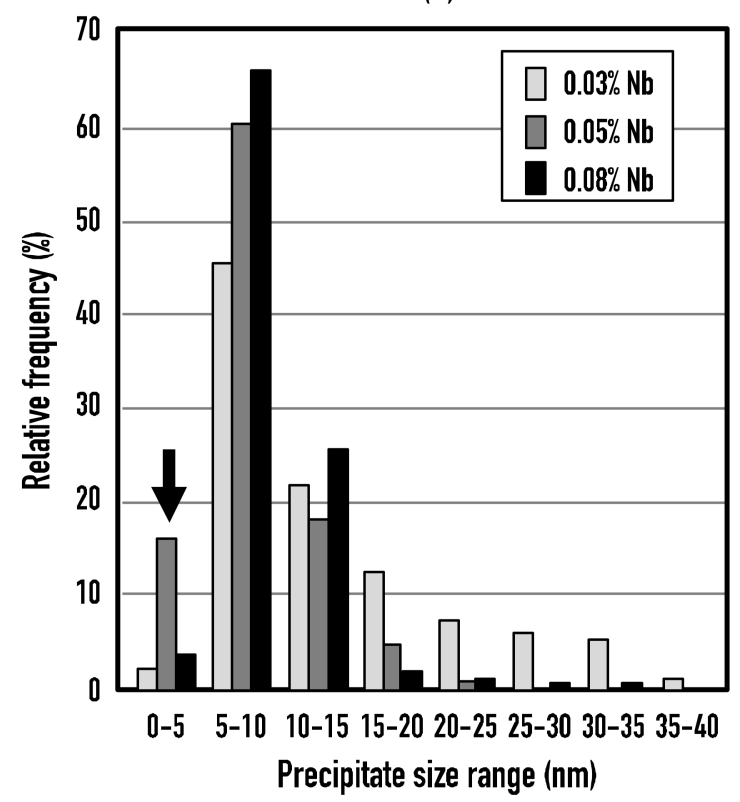

Figure 17. (a) Effect of niobium alloying on the hydrogen diffusion coefficient measured by hydrogen permeation tests; (b) size distribution of $\mathrm{NbC}$ precipitates measured by transmission elcectron microscopy analysis.

\subsection{Combined Approach against Hydrogen Embrittlement}

With increasing strength level of as-quenched martensitic steels, it will become necessary to combine several means of optimizing the resistance against hydrogen embrittlement. Parent austenite grain refinement, dispersion of ultra-fine precipitate particles, reinforcement of grain boundaries, and, generally, clean steelmaking practice are prerequisites for good performance at the highest strength level. Niobium microalloying provides both parent austenite grain refinement and particle dispersion. The particle size distribution can further be improved by the addition of molybdenum as it reduces the size of particle and thus increases the particle density. Simultaneously, molybdenum enhances grain boundary cohesion. It is further advisable to keep manganese additions low and to tightly limit phosphorous and sulphur residuals. Research in this respect is ongoing, yet first screening results indicate that the combination of individual approaches indeed brings about significant improvements. Figure 18 represents measured time-to-fracture improvements based after adding niobium and molybdenum, either single or combined, to grade 32MnB5 as shown before in Figure 16. The combined alloy effect is stronger than the sum of each individual effect, indicating a synergy between niobium and molybdenum in the alloy. 


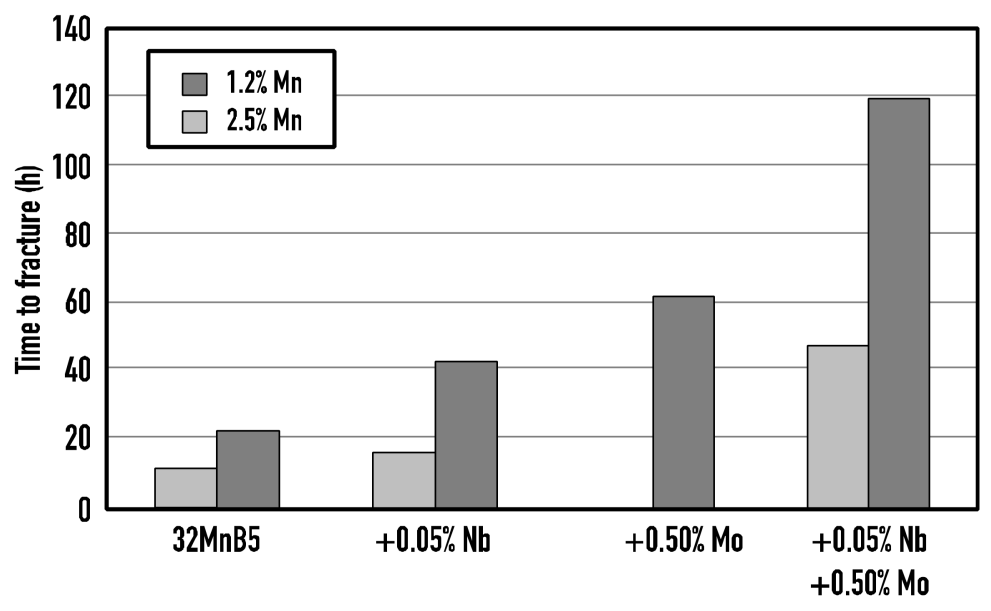

Figure 18. Effect of metallurgical optimization strategies on the delayed fracture resistance of a $2000 \mathrm{MPa}$ tensile strength steel (32MnB5) using Mo and Nb alloying (double-notched tensile sample immersed in $20 \%$ ammonium thiocyanate solution under constant load conditions with an acting stress of $1000 \mathrm{MPa}$ at the notch).

\section{Conclusions}

The presented results, originating from a large number of laboratory and industrial trials, confirmed that microstructural refinement is very efficient in optimizing the properties of as-quenched martensitic steels such as strength, toughness, ductile-to-brittle-transition temperature, and hydrogen embrittlement resistance. Although the definition of the effective grain size for each of these properties may refer to different microstructural features, the presented results indicated that in most cases the parent austenite grain size shows good correlation to respective properties in a Hall-Petch type relationship. This applies to both re-austenitizing quenched as well as direct quenched steels. In direct quenched steels with pancaked austenite morphology the grain thickness in the direction normal to the sheet surface defines the relevant parent austenite grain size.

The experimental data showed that the Hall-Petch coefficient for cleavage fracture stress appears to be significantly larger than the one for yield strength. Hence sufficiently strong grain refinement enables ductile fracture even at very low operating temperature. It was demonstrated that, by grain refinement, a significant strength increase can go along with a large drop in ductile-to-brittle transition temperature, contrary to all other strengthening mechanisms. Particularly in re-austenitizing quenched steels, parent austenite grain refinement effectively increases the upper-shelf impact energy. In direct quenched steels, toughness behavior is strongly anisotropic, having better properties in the rolling direction.

Because of their high yield strength, as-quenched martensitic steels are sensitive to hydrogen embrittlement causing delayed fracture phenomena under applied or residual stress. Parent austenite grain refinement was shown to be an efficient means of increasing the time-to-fracture by lowering the concentration of hydrogen on the grain boundary. Furthermore, hydrogen trapping by dispersed ultra-fine sized carbide precipitates can reduce the amount of diffusible hydrogen causing delayed fracture. Increasing the cohesion of parent austenite grain boundaries also counteracts decohesion caused by segregated hydrogen.

Molybdenum and niobium were demonstrated to be key alloying elements in this optimization strategy. Niobium provides efficient grain size control, actively in TMCP-based hot rolling processes and passively during re-austenitizing processes. Molybdenum not only provides high hardenability but adds to grain refinement by solute drag effects, optimizes the precipitation behavior of niobium, and increases grain boundary cohesion. The synergy between both alloying elements results in significantly improved delayed fracture resistance in martensitic steels of the highest strength level. 
In quenched steels of highest strength level, it is advisable to opt for a low manganese level. High manganese additions increase the sensitivity for hydrogen embrittlement.

Acknowledgments: Parts of this work have been financially supported by the International Molybdenum Association (IMOA), London, UK and CBMM, Sao Paulo, Brazil. The collaboration and experimental support by Okayama University (Takehide Senuma), National Taiwan University (Jer-Ren Yang), Oulu University (Jukka Kömi, David Porter), and University of Science and Technology Beijing (Yunhua Huang) is gratefully acknowledged.

Author Contributions: Hardy Mohrbacher co-designed the experimental work, contributed to the metallurgical interpretation of the experimental results, prepared the literature review, and wrote the paper.

Conflicts of Interest: The author declares no conflict of interest. The founding sponsors had no role in the design of the study; in the collection, analyses, or interpretation of data; in the writing of the manuscript, and in the decision to publish the results.

\section{References}

1. Leslie, W. The Physical Metallurgy of Steels; McGraw Hill: New York, NY, USA, 1981; pp. 216-226.

2. Krauss, G. Martensite in steel: Strength and structure. Mater. Sci. Eng. 1999, 273, 40-57. [CrossRef]

3. Belanger, P.J.; Hall, J.N.; Coryell, J.; Singh, J.P. Automotive Body Press-Hardened Steel Trends. In Proceedings of the International Symposium on the New Developments of Advanced High-Strength Steel, Vail, CO, USA, 23-27 June 2013; pp. 239-250.

4. Bian, J.; Mohrbacher, H. Novel Alloying Design for Press Hardening Steels with Better Crash Performance. In Proceedings of the International Symposium on the New Developments of Advanced High-Strength Steel, Vail, CO, USA, 23-27 June 2013; pp. 251-262.

5. Olsson, R.; Haglund, N.I. Cost effective fabrication of submarines and mobile cranes in high performance steels. Int. J. Join. Mater. 1991, 3, 120-128.

6. Sugimoto, K.-I. Fracture strength and toughness of ultra high strength TRIP aided steels. Mater. Sci. Technol. 2009, 25, 1108-1117. [CrossRef]

7. Nagumo, M. Function of Hydrogen in Embrittlement of High-strength Steels. ISIJ Int. 2001, 41, 590-598. [CrossRef]

8. Kaijalainen, A.J.; Suikkanen, P.; Karjalainen, L.P.; DeArdo, A.J. Effect of Austenite Conditioning in the Non-Recrystallization Regime on the Microstructures and Properties of Ultra High Strength Bainitic/Martensitic Strip Steel. In Proceedings of the 2nd International Conference on Super-High Strength Steels, Peschiera del Garda, Italy, 17-19 October 2010; Paper 115.

9. Schneider, A.S.; Cayla, J.L.; Just, C.; Schwinn, V. The Role of Niobium for the Development of Wear Resistant Steels with Superior Toughness. In Proceedings of the International Symposium on Wear Resistant Alloys for the Mining and Processing Industry, Campinas, Brazil, 4-7 May 2015; Mohrbacher, H., Ed.; TMS: Pittsburgh, PA, USA, 2018; pp. 173-186.

10. Speich, G.R. Tempering of low-carbon martensite. Trans. AIME 1969, 245, 2553-2564.

11. Guo, Z.; Lee, C.S.; Morris, J.W. On coherent transformations in steel. Acta Mater. 2004, 52, 5511-5518. [CrossRef]

12. Kinney, C.C.; Pytlewski, K.R.; Khachaturyan, A.G.; Morris, J.W. The microstructure of lath martensite in quenched 9Ni steel. Acta Mater. 2014, 69, 372-385. [CrossRef]

13. Morito, S.; Tanaka, H.; Konishi, R.; Furuhara, T.; Maki, T. The morphology and crystallography of lath martensite in Fe-C alloys. Acta Mater. 2003, 51, 1789-1799. [CrossRef]

14. Maki, T.; Tsuzaki, K. Tamura, K. The Morphology of Microstructure Composed of Lath Martensite. Trans. Iron Steel Inst. Jpn. 1980, 20, 207-214.

15. Morito, S.; Saito, H.; Ogawa, T.; Furuhara, T.; Maki, T. Effect of Austenite Grain Size on the Morphology and Crystallography of Lath Martensite in Low Carbon Steels. ISIJ Int. 2005, 45, 91-94. [CrossRef]

16. Qi, L.; Khachaturyan, A.G.; Morris, J.W. The microstructure of dislocated martensitic steel: Theory. Acta Mater. 2014, 76, 23-39. [CrossRef]

17. Morris, J.W.; Lee, C.S.; Guo, Z. The Nature and Consequences of Coherent Transformations in Steel. ISIJ Int. 2003, 43, 410-419. [CrossRef]

18. Cohen, M. The Strengthening of Steel. Trans. AIME 1962, 224, 638-657.

19. Cohen, M. On the Development of High Strength in Steel. JISI 1963, 201, 833-841. 
20. Tomita, Y.; Okabayashi, K. Effect of microstructure on strength and toughness of heat-treated low alloy structural steels. Metall. Trans. A 1986, 17, 1203-1209. [CrossRef]

21. Wang, C.; Wang, M.; Shi, J.; Hui, W.; Dong, H. Effect of Microstructure Refinement on the Strength and Toughness of Low Alloy Martensitic Steel. J. Mater. Sci. Technol. 2007, 23, 659-664.

22. Morito, S.; Ohba, T. Crystallographic Analysis of Characteristic Sizes of Lath Martensite Morphology. Fundamentals of Martensite and Bainite toward Future Steels with High Performance; Furuhara, T., Tsuzaki, K., Eds.; ISIJ: Tokyo, Japan, 2007; pp. 57-62.

23. Morris, J.W. On the Ductile-Brittle Transition in Lath Martensitic Steel. ISIJ Int. 2011, 51, $1569-1575$. [CrossRef]

24. Guo, Z.; Lee, C.S.; Morris, J.W. Grain Refinement for Exceptional Properties in High Strength Steel by Thermal Mechanisms and Martensitic Transformation. In Proceedings Workshop on New Generation Steel; Chinese Society for Metals: Beijing, China, 2001; pp. 48-54.

25. Ohmura, T.; Tsuzaki, K. A New Aspect of the Strengthening Factors of Fe-C Martensite through Characterization of Nanoindentation-induced Deformation Behavior. In Fundamentals of Martensite and Bainite toward Future Steels with High Performance; Furuhara, T., Tsuzaki, K., Eds.; ISIJ: Tokyo, Japan, 2007; pp. $35-46$.

26. Hannula, J.; Kömi, J.; Porter, D.A.; Somani, M.C.; Kaijalainen, A.; Suikkanen, P.; Yang, J.R.; Tsai, S.P. Effect of Boron on the Strength and Toughness of Direct-Quenched Low-Carbon Niobium Bearing Ultra-High-Strength Martensitic Steel. Metall. Mater. Trans. A 2017, 48, 5344-5356. [CrossRef]

27. Irani, J.J. Physical Properties of Martensite and Bainite; Special Report 93; The Iron and Steel Institute: Scarborough, UK, 1965; pp. 193-203.

28. Naylor, J.P.; Blondeau, B. The Respective Roles of the Packet Size and the Lath Width on Toughness. Metall. Trans. 1976, 7, 891-894. [CrossRef]

29. Naylor, J.P.; Krahe, P.R. Cleavage Planes in Lath Type Bainite and Martensite. Metall. Trans. 1975, 6, 594-598. [CrossRef]

30. Morris, J.W.; Kinney, C.; Pytlewski, K.; Adachi, Y. Microstructure and cleavage in lath martensitic steels. Sci. Tech. Adv. Mater. 2013, 14, 041208. [CrossRef] [PubMed]

31. Matsuda, S.; Inoue, T.; Mimura, H.; Okamura, Y. Toughness and Effective Grain Size in Heat-Treated Low-Alloy High-Strength Steels. Trans. ISIJ 1972, 12, 325-333.

32. Morris, J.W.; Guo, Z.; Krenn, C.R.; Kim, Y.-H. The Limits of Strength and Toughness in Steel. ISIJ Int. 2001, 41, 599-611. [CrossRef]

33. Hanamura, T.; Yin, F.; Nagai, K. Ductile-Brittle Transition Temperature of Ultrafine Ferrite/Cementite Microstructure in a Low Carbon Steel Controlled by Effective Grain Size. ISIJ Int. 2004, 44, 610-617. [CrossRef]

34. McMahon, C.J. Effects of Hydrogen on Plastic Flow and Fracture in Iron and Steel. Hydrogen Effects in Metals; Bernstein, I.M., Thompson, A.W., Eds.; TMS: Pittsburgh, PA, USA, 1981; Volume 219.

35. Kim, Y.H. A Study of Hydrogen Embrittlement in Lath Martensitic Steels. Ph.D. Thesis, Department of Materials Science and Engineering, University of California, Berkeley, CA, USA, 1985.

36. Kim, Y.H.; Morris, J.W. The nature of quasicleavage fracture in tempered 5.5Ni steel after hydrogen charging. Metall. Trans. 1983, 14, 1883-1888. [CrossRef]

37. Kim, Y.H.; Kim, H.J.; Morris, J.W. The influence of precipitated austenite on hydrogen embrittlement in $5.5 \mathrm{Ni}$ steel. Metall. Trans. 1986, 17, 1157-1164. [CrossRef]

38. Yusa, S.; Hara, T.; Tsuzaki, K.J. Grain boundary carbide structure in tempered martensitic steel with serrated prior austenite grain boundaries. Jpn. Inst. Met. 2000, 64, 1230-1238. [CrossRef]

39. Takeda, Y.; McMahon, C.J. Strain controlled vs stress controlled hydrogen induced fracture in a quenched and tempered steel. Met. Trans. A 1981, 12, 1255-1266. [CrossRef]

40. Grange, R.A.; Hibral, C.R.; Porter, L.F. Hardness of Tempered Martensite in Carbon and Low-alloy Steels. Metall. Trans. A 1977, 8, 1775-1785. [CrossRef]

41. Mohrbacher, H. Laser welding of modern automotive high strength steels. In Proceedings of the 5th International Conference on HSLA Steels (2005), Sanya, Hainan, China, 8-10 November 2005; pp. 582-586.

42. Takaki, S.; Ngo-Huynh, K.-L.; Nakada, N.; Tsychiyama, T. Strengthening Mechanism in Ultra Low Carbon Martensitic Steel. ISIJ Int. 2012, 52, 710-716. [CrossRef] 
43. Geng, W.T.; Freeman, A.J.; Olson, G.B. Influence of alloying additions on grain boundary cohesion of transition metals: First-principles determination and its phenomenological extension. Phys. Rev. B 2001, 63, 165415. [CrossRef]

44. Lin, H.-R.; Cheng, G.-H. Analysis of hardenability effect of boron. Mater. Sci. Technol. 1990, 6, 724-729. [CrossRef]

45. Kern, A.; Schriever, U. Niobium in Quenched and Tempered HSLA-Steels. In Recent Advances of Niobium Containing Materials in Europe; Verlag Stahleisen: Düsseldorf, Germany, 2005; pp. 107-120.

46. Kern, A.; Müsgen, B.; Schriever, U. Effect of Boron in Quenched and Tempered Steels. Thyssen Tech. Ber. 1990, 1, 43-52.

47. Nowill, C.A.; Speer, J.G.; De Moor, E.; Matlock, D.K. Effect of Austenitizing Conditions on Hardenability of Boron-Added Microalloyed Steel. AIST Iron Steel Technol. 2012, 10, 111-120.

48. Ishikawa, N.; Ueda, K.; Mitao, S.; Murotav, Y.; Sakiyama, T. High-Performance Abrasion-Resistant Steel Plates with Excellent Low-Temperature Toughness. In Proceedings of the International Symposium on the Recent Developments in Plate Steels, Winter Park, CO, USA, 19-22 June 2011; pp. 82-91.

49. Tobie, T.; Hippenstiel, F.; Mohrbacher, H. Optimizing Gear Performance by Alloy Modification of Carburizing Steels. Metals 2017, 7, 415. [CrossRef]

50. Gangloff, R.P. Critical Issues in Hydrogen Assisted Cracking of Structural Alloys, in Environment Induced Cracking of Metals (EICM-2); Shipilov, S., Ed.; Elsevier Science: Oxford, UK, 2008; pp. 2-24.

51. Senuma, T.; Takemoto, Y. Influence of Nb Content on Delayed Fracture and Crash Relevant Properties of $2000 \mathrm{MPa}$ class hot stamping steel sheets. In Proceedings of the International Conference on Steels in Cars and Trucks, Amsterdam, The Netherlands, 2017.

52. Momotani, Y.; Shibata, A.; Terada, D.; Tsuji, N. Effect of strain rate on hydrogen embrittlement in low-carbon martensitic steel. Int. J. Hydrog. Energy 2017, 42, 3371-3379. [CrossRef]

53. Lee, S.J.; Ronevich, J.A.; Krauss, G.; Matlock, D.K. Hydrogen Embrittlement of Hardened Low-carbon Sheet Steel. ISIJ Int. 2010, 50, 294-301. [CrossRef]

54. Lovicu, G.; Barloscio, M.; Bottazzi, M.; D'Aiuto, F.; De Sanctis, M.; Dimatteo, A.; Federici, C.; Maggi, S.; Santus, C.; Valentini, R. Hydrogen Embrittlement of Advanced High Strength Steels for Automotive Use. In Proceedings of the 2nd International Conference on Super High Strength Steels, Verona, Italy, 17-20 October 2010.

55. Zhang, S.; Huang, Y.; Sun, B.; Liao, Q.; Lu, H.; Jian, B.; Mohrbacher, H.; Zhang, W.; Guo, A.; Zhang, Y. Effect of $\mathrm{Nb}$ on hydrogen-induced delayed fracture in high strength hot stamping steels. Mater. Sci. Eng. A 2015, 626, 136-143. [CrossRef]

56. Pressouyre, G.M. Current Solutions to Hydrogen Problems in Steels. In Proceedings of the First International Conference on Current Solutions to Hydrogen Problems in Steels, Washington, DC, USA, 1-5 November 1982; pp. 18-36.

57. Wei, F.-G.; Hara, T.; Tsuzaki, K. Nano-Preciptates Design with Hydrogen Trapping Character in High Strength Steel. ASM Int. 2009, 448-455. [CrossRef]

(c) 2018 by the author. Licensee MDPI, Basel, Switzerland. This article is an open access article distributed under the terms and conditions of the Creative Commons Attribution (CC BY) license (http:/ / creativecommons.org/licenses/by/4.0/). 